Centre interuniversitaire de recherche en economie quantitative

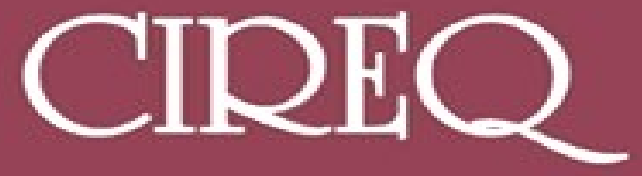

Cahier 15-2005

COSTS OF BUSINESS CYCLES FOR UNSKILLED WORKERS

Toshihiko MUKOYAMA and Ayşegül ŞAHIN 


\section{Cahier 15-2005}

COSTS OF BUSINESS CYCLES FOR UNSKILLED WORKERS

Toshihiko MUKOYAMA and Ayşegül ŞAHIN 


\section{CIREQ}

Le Centre interuniversitaire de recherche en économie quantitative (CIREQ) regroupe des chercheurs dans les domaines de l'économétrie, la théorie de la décision, la macroéconomie et marchés financiers, la microéconomie appliquée et économie expérimentale et l'économie de l'environnement et des ressources naturelles. Ils proviennent principalement des universités de Montréal, McGill et Concordia. Le CIREQ offre un milieu dynamique de recherche en économie quantitative grâce au grand nombre d'activités qu'il organise (séminaires, ateliers, colloques) et de collaborateurs qu'il reçoit chaque année.

The Center for Interuniversity Research in Quantitative Economics (CIREQ) regroups researchers in the fields of econometrics, decision theory, macroeconomics and financial markets, applied microeconomics and experimental economics, and environmental and natural resources economics. They come mainly from the Université de Montréal, McGill University and Concordia University. CIREQ offers a dynamic environment of research in quantitative economics thanks to the large number of activities that it organizes (seminars, workshops, conferences) and to the visitors it receives every year.

\section{Cahier 15-2005}

COSTS OF BUSINESS CYCLES FOR UNSKILLED WORKERS

Toshihiko MUKOYAMA and Ayşegül ŞAHIN

CIREQ, Université de Montréal C.P. 6128 , succursale Centre-ville Montréal (Québec) H3C 3J7 Canada téléphone : (514) 343-6557

télécopieur : (514) 343-5831 cireq@umontreal.ca http://www.cireq.umontreal.ca

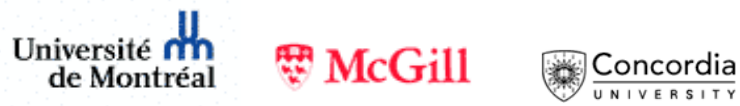


Ce cahier a également été publié par le Département de sciences économiques de Concordia University sous le numéro 05002.

This working paper was also published by the Department of Economics of Concordia University, under number 05002.

Dépôt légal, Bibliothèque nationale du Canada, 2005, ISSN 0821-4441

Dépôt légal, Bibliothèque nationale du Québec, 2005, ISBN 2-89382-509-5 


\title{
Costs of Business Cycles for Unskilled Workers*
}

\author{
Toshihiko Mukoyama ${ }^{\dagger}$ \\ Department of Economics \\ Concordia University \\ and \\ CIREQ
}

\author{
Ayşegül Şahin \\ Federal Reserve Bank of New York
}

June 1, 2005

\begin{abstract}
This paper reconsiders the cost of business cycles under market incompleteness. Primarily, we focus on the heterogeneity in the cost among different skill groups. Unskilled workers are subject to a much larger risk of unemployment during recessions than are skilled workers. Moreover, unskilled workers earn less income, which limits their ability to self-insure. We examine how this heterogeneity in unemployment risk and income translates into heterogeneity in the cost of business cycles. We find that the welfare cost of business cycles for unskilled workers is substantially higher than the welfare cost for skilled workers.
\end{abstract}

Keywords: Cost of Business Cycles; Incomplete Markets; Skill and Unemployment

JEL Classifications: E24; E32; E61

*This paper was previously entitled "Heterogeneous Costs of Business Cycles with Incomplete Markets". We thank Robert King, the Editor, for detailed comments and suggestions. Discussions with Per Krusell and Tony Smith were very helpful. We thank Sun-Bin Kim for his help in Fortran programming. We also thank Kartik Athreya, Mark Bils, Emanuela Cardia, Rui Castro, Andreas Hornstein, Igor Livshits, and seminar participants at Bank of Japan, Doshisha, Illinois at Urbana-Champaign, Indiana, Keio, Kobe, New York Fed, Richmond Fed, Texas A\&M, Tokyo, Waseda, the Montreal Macro Reading Group, the Rochester Wegmans Conference, the CEA Annual Meetings 2003, and the SED Meetings 2003 for comments and suggestions. We thank Vera Brencic and Roxanne Stanoprud for excellent research assistance. Mukoyama thanks FQRSC and SSHRC for financial support. The views expressed in this article are those of the authors and do not necessarily reflect the position of the Federal Reserve Bank of New York or the Federal Reserve System.

${ }^{\dagger}$ Corresponding author. Address: Department of Economics, Concordia University, 1455 de Maisonneuve Blvd. West, Montreal, QC, H3G 1M8, Canada. Tel: +1-514-848-2424 ext. 3927. Fax: +1-514-848-4536. E-mail address: mukoyama@alcor.concordia.ca. 


\section{Introduction}

In everyday discussions of economic policy, it is usually assumed that business cycles are harmful and that it is beneficial to eliminate them. Many would agree that stabilization is beneficial if it comes without cost. However, stabilization policies are often very costly, and it is not obvious whether we should avoid business cycles when the cost of doing so is large. What, in fact, is the cost of having business cycles? How much resource cost can be justified to eliminate business cycles? In an influential study, Lucas (1987) considered these questions. His result was astounding — the cost of having business cycles is almost zero. ${ }^{1}$

Lucas's use of a representative agent and an aggregate consumption series are justified in an environment where complete Arrow-Debreu markets exist. Under complete asset markets and a common constant relative risk aversion utility function, the aggregation theorem holds and the consumption series of each individual will parallel the aggregate consumption series. In reality, however, it is unlikely that asset markets are complete. ${ }^{2}$

Under incomplete markets, the costs of business cycles may be larger than the cost in the representative-agent framework, since individuals have only a limited set of devices to insure themselves from the shocks. ${ }^{3}$ More importantly, since individual consumption paths do not parallel the aggregate consumption path, it is possible that the cost of business cycles differ across individuals.

In recent papers, Krusell and Smith $(1999,2002)$ pointed out that the cost of business cycles may differ among different groups of people. For example, agents with larger asset holdings would have a greater opportunity to self-insure against unemployment risk. It is expected that very poor agents would have a larger cost of business cycles. Krusell and Smith $(1999,2002)$ reported that there is considerable heterogeneity in the cost of business cycles

\footnotetext{
${ }^{1} \mathrm{He}$ finds that the welfare cost is $0.008 \%$ of the steady-state consumption when the representative agent has logarithmic utility.

${ }^{2}$ See Obstfeld (1994) and Barlevy (2004) for other critiques of Lucas's approach.

${ }^{3}$ See İmrohoroğlu (1989), Atkeson and Phelan (1994), and Krusell and Smith (1999, 2002) for this point.
} 


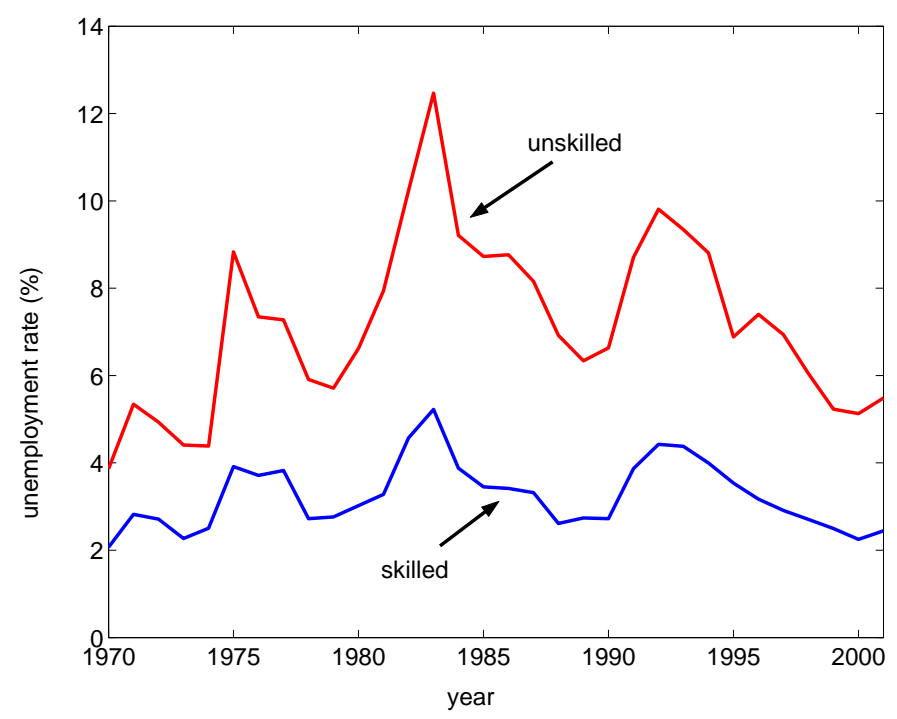

Figure 1: Unemployment Rates by Skill.

Data Source: Current Population Survey

among agents with different wealth.

The analysis by Krusell and Smith $(1999,2002)$ abstracts from an important source of heterogeneity - difference in skills. Figure 1 is drawn using annual data from the Current Population Survey (1970-2001). It illustrates the unemployment processes for unskilled workers (high school diploma or lower) and for skilled workers (some college or above). The two processes differ dramatically. Unskilled workers are not only subject to a higher level of unemployment, but also face a more volatile unemployment process. This implies that unskilled workers are hurt more by recessions. ${ }^{4}$ Moreover, unskilled workers earn less income, which limits their ability to self-insure. We examine how this heterogeneity in unemployment risk and income translates into heterogeneity in the cost of business cycles.

To this end, we set up a dynamic general equilibrium model with incomplete markets. In the model, there is heterogeneity in skills, employment status, and the discount factor. In

\footnotetext{
${ }^{4}$ Mincer (1991) documented that unskilled workers are subject to a substantially larger risk of becoming unemployed in recessions than are skilled workers. Topel (1993) shows that the unemployment rate of low-wage men is not only higher, but also much more volatile.
} 
addition, the heterogeneity in asset holding is endogenously generated. The heterogeneity in skills are represented by the differences in earnings and the unemployment process.

We find that the welfare cost of business cycles for unskilled individuals, who suffer from unemployment more frequently and are more likely to have binding borrowing constraints, is substantially higher than the cost for the representative agent in complete-market models or the average cost in incomplete-market models.

On average, our quantitative results are comparable to the previous results obtained by Atkeson and Phelan (1994) and Krusell and Smith (1999, 2002). However, the average number masks a substantial heterogeneity in the model. In our first experiment, which assumes that the fluctuations are eliminated during a boom, the gain from eliminating business cycles is $0.043 \%$ (of steady-state consumption) for unskilled workers, while skilled workers gain only 0.005\%. In the second experiment, which assumes that fluctuations are eliminated during a recession, unskilled workers gain $0.119 \%,{ }^{5}$ while skilled workers gain $0.043 \%$. Further, a borrowing-constrained, unskilled, and unemployed agent can gain $0.622 \%$ from eliminating business cycles, which is nearly eighty times larger than the number found using the representative-agent framework.

This paper is organized as follows. The next section describes our baseline model. In Section 3 we analyze the welfare effects of removing business cycles. Section 4 concludes.

\section{Model}

This section describes the environment and solves the model economy.

\footnotetext{
${ }^{5}$ Note that this figure is larger than any of the average gains obtained in Krusell and Smith's (2002) experiments, which assumes longer unemployment durations than in our calibration. When we calibrate our model with similar unemployment processes as Krusell and Smith (2002), the gains for unskilled workers in both experiments are larger than Krusell and Smith's (2002) average gains. See Appendix E for details.
} 


\subsection{Setup}

Our model is a standard Bewley-Huggett-Aiyagari type dynamic general equilibrium model with incomplete markets (Aiyagari [1994]). In particular, we build upon the model with aggregate shocks developed by Krusell and Smith (1998).

There is a continuum of agents, with measure 1, in the economy. They maximize their discounted utility

$$
\mathbf{U}=E_{0}\left[\sum_{t=0}^{\infty}\left(\prod_{j=0}^{t} \beta_{j}\right) \log c_{t}\right],
$$

where $c_{t}$ is the consumption in period $t$ and $\beta_{0}=1$. We allow the discount factor $\beta_{t}$ to differ across agents and to vary over time. In particular, $\beta_{t}$ is assumed to be stochastic and follow a Markov process. At each point in time, some agents are more patient than others. We interpret each agent as an altruistic dynasty. Each agent's patience level may differ across generations. This formulation serves as a device to produce a realistic wealth distribution. ${ }^{6}$

There are two types of agents: skilled $(\eta=s)$ and unskilled $(\eta=u)$. Each agent's skill status, $\eta$, may change over time by a stochastic process that is uncorrelated across agents, but the number of skilled $\left(\chi_{s}\right)$ and unskilled $\left(\chi_{u}\right)$ workers is constant, by the law of large numbers. A skilled worker can supply more labor than an unskilled worker. We express this dependence by the function $\phi(\eta)$, where $\phi(s)>\phi(u)$. The value $\phi(s) / \phi(u)$ can be interpreted as the skill premium. We assume that $\phi(\eta)$ is constant over time. The skill premium is, therefore, acyclical. ${ }^{7}$

An agent is either employed $(\epsilon=1)$ or unemployed $(\epsilon=0)$. The employment status is determined by an exogenous random process. When employed, the agent supplies $\phi(\eta)$ units of labor to the market. When unemployed, she engages in household production. Household production utilizes the same technology as the market technology ${ }^{8}$ but the agent can supply

\footnotetext{
${ }^{6}$ This method was developed by Krusell and Smith (1998).

${ }^{7}$ This assumption is motivated by the empirical studies by Keane and Prasad (1993) and Lindquist (2004).

${ }^{8}$ It is implicitly assumed that a worker can rent capital for household production without limit. This assumption is not inconsistent with the household borrowing constraint, introduced below, if the household
} 
only a fraction $h<1$ of her market labor supply. Thus, she is less efficient at home than in the market. ${ }^{9}$ The probability of becoming unemployed differs between skilled and unskilled agents. The unemployment probability also depends on the aggregate state of the economy.

The market technology is represented by the aggregate production function

$$
Y=z \bar{k}^{\alpha} \bar{n}^{1-\alpha}
$$

where $\bar{k}$ is the aggregate capital and $\bar{n}$ is the aggregate labor, including the labor supplied for household production. The economy is subject to aggregate shocks. The aggregate state is either good or bad. In a good state, $z=g$ and the unemployment rate for skill level $\eta$ is $\mu_{\eta}^{g}$. In a bad state, $z=b$ and the unemployment rate for skill level $\eta$ is $\mu_{\eta}^{b}$. We assume that $g>b$ and $\mu_{\eta}^{g}<\mu_{\eta}^{b}$ for $\eta=s, u$; i.e., productivity is higher and the unemployment rate is lower in booms than in recessions.

We assume that there are no insurance markets for the idiosyncratic shocks. Agents can hold only one kind of asset - capital. Holding a negative amount of capital (borrowing) is allowed up to an exogenous limit $\underline{k}$.

Aggregate capital and labor are given by

$$
\begin{gathered}
\bar{k}=\int_{J} k_{j} d j \\
\left.\bar{n}=\sum_{\eta=s, u} \phi(\eta) \chi_{\eta}\left\{\left(1-\mu_{\eta}^{z}\right)+h \mu_{\eta}^{z}\right)\right\},
\end{gathered}
$$

where $J$ is the set of agents and $k_{j}$ is the capital holding of an agent $j$. The markets are competitive, so the interest rate $r$ and the wage $w$ are determined by their marginal products. Each household's period-by-period budget constraint is

$$
c+k^{\prime}=r k+w \phi(\eta) \theta(\epsilon)+(1-\delta) k,
$$

production capital can be perfectly collateralized.

${ }^{9}$ This assumption is made so that an agent can earn some labor income even when she is unemployed. Alternatively, we can introduce an unemployment insurance system à la Hansen and İmrohoroğlu (1992). In this case, a government and its budget constraint would need to be incorporated into our setup. 
where

$$
\theta(\epsilon)= \begin{cases}h & \text { if } \epsilon=0, \\ 1 & \text { if } \epsilon=1,\end{cases}
$$

$k^{\prime}$ is the next period's capital, and $\delta$ is the depreciation rate of capital.

\subsection{Probability Structure}

There are two types of exogenous shocks: aggregate and idiosyncratic. The aggregate state evolves stochastically following a Markov process. The probability of moving from state $z$ to state $z^{\prime}$ is denoted as $p_{z z^{\prime}}$.

There are three idiosyncratic shocks: $\epsilon, \beta$, and $\eta$. Following the standard Bewley-style model, the individual employment process is treated as an exogenous stochastic process. Idiosyncratic employment shocks $\epsilon \in\{0,1\}$ follow a Markov process with transition probability $\pi_{\epsilon \epsilon^{\prime}}^{z z^{\prime} \eta^{\prime}}$. Following the tradition of İmrohoroğlu (1989), we assume that the probability of becoming unemployed next period $\left(\epsilon^{\prime}=0\right)$ depends not only on the current employment status $(\epsilon)$, but also on the current and next period's aggregate state $\left(z\right.$ and $\left.z^{\prime}\right)$. Additionally, to reflect the heterogeneity exhibited in Figure 1, the probability of becoming unemployed depends on the skill level in the next period $\left(\eta^{\prime}\right)$.

The discount factor $\beta$ is assumed to be stochastic. We assume that $\beta$ 's process is independent of the other aggregate and idiosyncratic state variables. The Markov transition probability is denoted as $\omega_{\beta \beta^{\prime}}$.

We assume that the individual skill level $\eta \in\{u, s\}$ follows an exogenous stochastic process. This transition probability is denoted as $q_{\eta \eta^{\prime}}$. Again, we can interpret each agent as an altruistic dynasty. Within each dynasty, the skill level may differ across generations. The probability $q_{\eta \eta^{\prime}}$ reflects the intergenerational mobility of skill levels. ${ }^{10}$ The skill transition process is assumed to be independent of the other state variables.

\footnotetext{
${ }^{10}$ In our formulation, the timing of the switch in $\beta$ and $\eta$ may not coincide. Synchronizing these processes is possible, but it complicates the analysis considerably and would not substantially alter our main results.
} 


\subsection{Recursive Competitive Equilibrium}

Let $\Gamma$ denote the measure of agents over $(k, \epsilon, \eta, \beta)$. The state variables relevant to each individual are the aggregate state variables $(z, \Gamma)$ and the idiosyncratic state variables $(k, \epsilon, \eta, \beta)$. Let $\mathbf{T}$ denote the equilibrium transition function for $\Gamma$ :

$$
\Gamma^{\prime}=\mathbf{T}\left(\Gamma, z, z^{\prime}\right)
$$

Then, the recursive competitive equilibrium can be defined in a standard manner. In the recursive competitive equilibrium, consumers and firms optimize given the state variables and the transition function $\mathbf{T}$. The markets for capital and labor clear, and the transition function is consistent with the individual decision rules. See Appendix A for the formal definition.

\subsection{Calibration}

But for some deviation, we follow a standard calibration. One period is considered to be six weeks. ${ }^{11}$ We choose $\delta=0.0125$ and the average value of $\beta$ as 0.995 . The capital share $\alpha=0.36$. The household production parameter $h$ is assumed to be 0.1 . These numbers closely follow the calibration of Krusell and Smith (1999, 2002). The borrowing constraint $\underline{k}$ is set at -13 , which is tighter than the "always payback constraint". This number is chosen so that the fraction of the people with negative wealth mimics the actual data. In the following we briefly discuss the calibration of other parameters and stochastic processes. The details of the calibration can be found in Appendix B.

Aggregate shocks take the values $z \in\{b, g\}=\{0.99,1.01\}$. Following Krusell and Smith $(1999,2002)$ we set the average business cycle duration to 2 years. From $1 /\left(1-p_{b b}\right)=$ $1 /\left(1-p_{g g}\right)=16, p_{b b}=p_{g g}=0.9375$.

\footnotetext{
${ }^{11}$ The choice of six weeks is the standard one in the unemployment insurance literature (see, for example, Hansen and İmrohoroğlu [1992]). In the business cycle literature, the choice of one quarter as a period is more popular (including Krusell and Smith [1998, 1999, 2002]). However, we calibrate the average unemployment duration in a "good" state to be 12.4 weeks, and as a consequence, we cannot use one quarter (13 weeks) to be a period choice.
} 
The skill transition probabilities are calibrated by assuming that the transition probability from skilled (college graduate) to skilled is 0.65 , and the transition probability from unskilled (high school graduate) to skilled is 0.35 for each generation. ${ }^{12}$ This restriction provides $q_{u u}=q_{s s}=0.9975$.

Calibrating individual employment shocks requires using data about unemployment rates and unemployment durations for different skill groups. We compute unemployment rates for the skilled and unskilled workers by using the Current Population Survey. Since the average duration of unemployment is similar across different skill groups (Mincer [1991]), we use the same unemployment durations for the skilled and the unskilled.

We assume that the discount factor $\beta_{t}$ follows a three-point Markov stochastic process. The three values of $\beta_{t}$ are pinned down so that the resulting distribution of asset holdings mimics the real wealth distribution. In particular, $\beta_{l}=0.9923, \beta_{m}=0.995$, and $\beta_{h}=0.9977$. We calibrate the Markov transition matrix by following Krusell and Smith's (1998) approach.

In the model, $\phi(s) / \phi(u)$ is the skill premium. To calibrate $\phi(s) / \phi(u)$, we use the estimates of Murphy and Welch (1992). They compute the ratio of the average wage of college graduate workers to high-school graduate workers for different experience groups and for several years. They find that this ratio, which can be interpreted as the skill premium, is between 1.37 to 1.58. To be consistent with their estimates, we set $\phi(s) / \phi(u)$ to $1.50 .^{13}$

\subsection{Model Solution}

Generally, it is computationally burdensome to solve this type of model. The state variables in the individual optimization include the economy-wide wealth distribution, which is an

\footnotetext{
${ }^{12}$ Mayer (2002, Table 1) shows that in PSID data, the intergenerational transition probability (between fathers and sons) from no-college to college is 35\%, while college to college is $73 \%$. Statistics Canada (1998, p.37) compares the intergenerational transition of schooling attainment across countries. It shows that in the United States, $64.2 \%$ of the population attains postsecondary schooling if their parents attained postsecondary education. If the parents attain only secondary education, the percentage drops to $35.7 \%$.

${ }^{13}$ One can also calibrate $\phi(s) / \phi(u)$ by using the estimates for return to college education. If one assumes that the return to one year of college education is $10 \%$, which is consistent with the estimates in Card (1995), then $\phi(s) / \phi(u)$ is around 1.50 .
} 
infinite-dimensional object. In our model, the wealth distribution is included in the state variables, since this information is necessary for predicting the next-period prices for each aggregate state. To predict these prices, the agents have to predict the next period's aggregate capital, which requires knowledge of the current period's wealth distribution. Krusell and Smith (1998) developed a computational method to overcome this obstacle. They found that the knowledge of only a few moments of the wealth distribution is often sufficient for predicting the next period's aggregate capital. In fact, they demonstrated that a linear prediction rule based only on the first moment $\bar{k}$ provides a very accurate prediction. They call their method "approximate aggregation".

In our model, we postulate a prediction rule

$$
\ln \bar{k}^{\prime}=\alpha_{0}+\alpha_{1} \ln \bar{k}+\alpha_{2} \ln z
$$

The "approximate aggregation" method works very well in our setting - the linear prediction rule with coefficients $\alpha_{0}=0.1258, \alpha_{1}=0.9747$, and $\alpha_{2}=0.0849$ provides a very accurate prediction. The $R^{2}$ of this prediction rule is 0.99997 . This implies that almost all the variation in $\bar{k}^{\prime}$ can be explained by the predicted value in the right-hand-side. The resulting equilibrium can therefore be viewed as very close to the rational expectations equilibrium.

The aggregate capital fluctuates between the values $\bar{k}=139.8$ and $\bar{k}=148.4$. The average value of $\bar{k}$ is 143.9. On average, skilled agents hold $k=176.1$ and unskilled agents hold $k=$ 111.7. Since the earning ratio is $1: 1.5$, the difference in asset holdings is more pronounced than the earnings difference. ${ }^{14}$ This large difference in asset holdings is important, since wealth holdings are the only means of self-insurance for unemployment in our incompletemarket setting.

The wealth distribution is matched to the data. In the data, ${ }^{15}$ the Gini coefficient of the

\footnotetext{
${ }^{14}$ This property can also be seen in data. The average wealth-earnings ratio of a college graduate is higher than that of a high school graduate. See Budría Rodríguez, Díaz-Giménez, Quadrini, and Ríos-Rull (2002).

${ }^{15}$ All the data in this paragraph are drawn from Budría Rodríguez, Díaz-Giménez, Quadrini, and Ríos-Rull (2002). Wolff (1995) employs a slightly different definition of wealth (the most notable difference is that he
} 

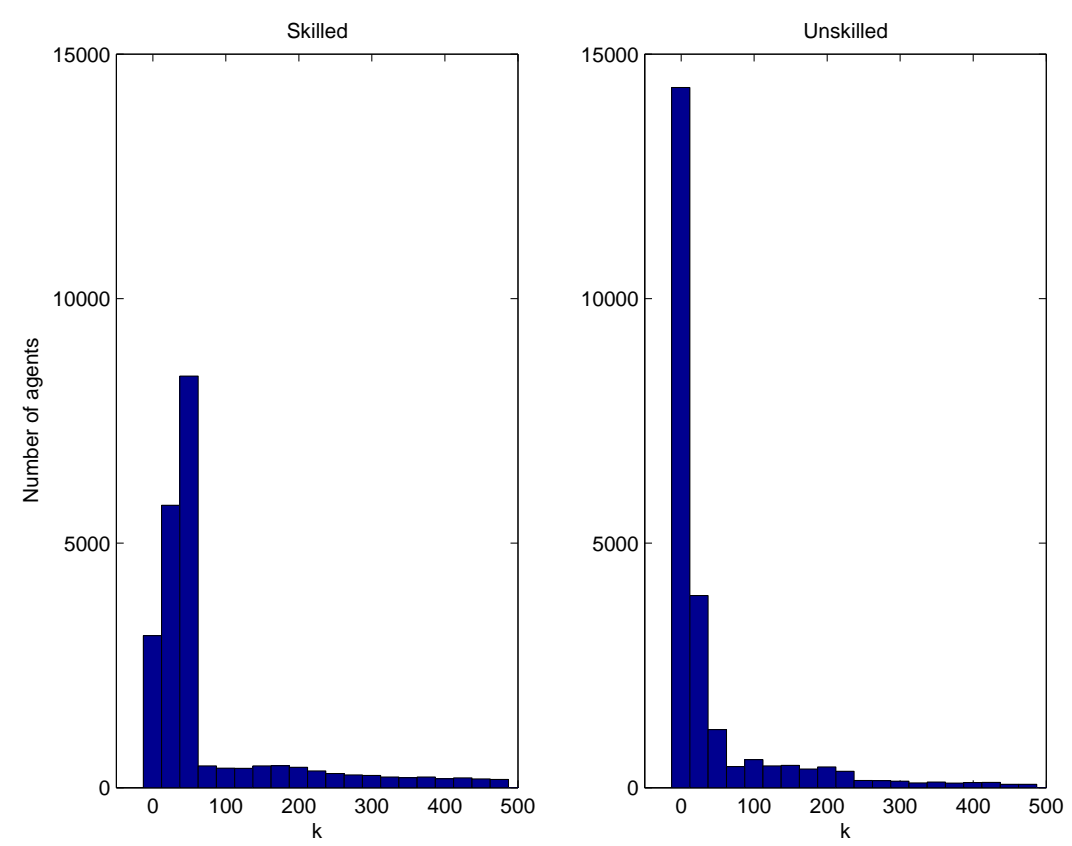

Figure 2: Wealth distributions for the skilled and the unskilled (truncated at $k=500$ )

wealth distribution is 0.80 , while in the model, it is 0.79 . In the right tail of the distribution, the top $10 \%$ of wealth-rich people hold about $69 \%$ of the real economy's total wealth, while $68 \%$ of wealth is held by the top $10 \%$ in the model. In the data, the top $20 \%$ (fifth wealth quintile) hold $82 \%$ of the total wealth, while the corresponding number is $85 \%$ in the model. In the left tail of the distribution, in the model, $7.2 \%$ of the agents hold negative wealth and additional $1.8 \%$ of agents hold wealth less than 1 (the average wage of an unskilled worker is about 3.6 ). In the data, $7.4 \%$ of the population report negative wealth and $2.5 \%$ report zero wealth.

The model produces a substantial heterogeneity in asset holdings. As is expected, there is a large difference in asset holdings across different $\beta$ : the average value of $k$ is 47.6 for $\beta=\beta_{l}$, 124.3 for $\beta=\beta_{m}$, and 382.5 for $\beta=\beta_{h}$. Asset distributions are very different between skilled agents and unskilled agents. About $2 \%$ of individuals hold negative wealth within the group does not include vehicles and pension plans). In Wolff (1995), the top $20 \%$ hold $85 \%$ of the total wealth and the Gini coefficient is 0.84 . 
of skilled agents, while nearly $16 \%$ of unskilled agents fall into this category. About a quarter of unskilled people own less wealth than their average wage level. The model produces more wealth inequality within unskilled agents than within skilled agents: Gini coefficients are 0.85 and 0.73 , respectively. Both groups contain wealth-rich people: $1.3 \%$ of the unskilled and $2.3 \%$ of the skilled own more than ten times the average wealth. Figure 2 shows the wealth distributions for the skilled and the unskilled workers. (The total number of agents is 50,000. We truncated the Figure at the upper bound of $k=500$.) Clearly, there are more unskilled workers who are close to the borrowing constraint.

\section{Removing Business Cycles}

The main question to be answered is: What will happen to individuals' welfare when business cycles are eliminated? To answer this, we follow Lucas's tradition in not describing specific policies to eliminate cycles. We directly eliminate shocks that are driving the aggregate fluctuations. The elimination is permanent, and this event is unanticipated by the agents.

\subsection{Aggregate Shocks}

Since the aggregate shocks are the driving force of the business cycles, a natural way to eliminate cycles is to replace the aggregate stochastic process by a deterministic process. In the spirit of Lucas, we replace the aggregate stochastic process by its conditional mean. The aggregate state $z$ starts at $z=1.01$ or $z=0.99$, depending on the timing of the removal, and $z$ converges monotonically to the value 1 , which is the unconditional mean of $z$.

\subsection{Idiosyncratic Shocks}

We assume that when the business cycles are eliminated, the part of the idiosyncratic risk which is correlated with the aggregate shocks is also eliminated. Krusell and Smith (1999, 2002), who first proposed this procedure coined it the "integration principle". Formally, when an idiosyncratic random variable $y$ can be written as a function $\bar{g}(i, z)$ of the aggregate 
variable $z$ and a random variable $i$ which is independent from $z$, then the new idiosyncratic variable after the elimination of the cycles is given by

$$
\hat{y}(i)=\int \bar{g}(i, z) f_{z}(z) d z
$$

with density $f_{i}(i)$ for each $i$. Here, $f_{z}(z)$ and $f_{i}(i)$ are the marginal density functions for $z$ and $i$, respectively.

As an example, ${ }^{16}$ consider an individual variable $y=z+i$, where $z \sim N\left(\mu_{z}, \sigma_{z}^{2}\right)$ and $i \sim N\left(\mu_{i}, \sigma_{i}^{2}\right)$ [thus, $\left.y \sim N\left(\mu_{z}+\mu_{i}, \sigma_{z}^{2}+\sigma_{i}^{2}\right)\right]$. Our procedure results in $\hat{y}(i)=\mu_{z}+i$. Since $i \sim N\left(\mu_{i}, \sigma_{i}^{2}\right)$, it follows that $\hat{y}(i) \sim N\left(\mu_{z}+\mu_{i}, \sigma_{i}^{2}\right)$. Notice that the mean is the same between $y$ and $\hat{y}(i)$, but the variance is reduced after applying the integration principle.

In our model, the individual random variable $\epsilon$ is a two-state Markov process, so the decomposition is more complicated. Krusell and Smith (2002) have shown how to construct idiosyncratic shocks in this case using the integration principle, and have developed a state representation for the distribution of these shocks. In general, the distribution of idiosyncratic shocks is time-varying when there is an unanticipated and permanent elimination of business cycles. For our purposes, since we have heterogeneity in skill levels, an extension of the Krusell-Smith approach is necessary. See Appendix C for details.

The resulting employment process $\hat{y}$ has less dispersion than $\epsilon$. Simulating for 10,000 periods, it turns out that the coefficient of variation of $\hat{y}$ is approximately $15 \%$ smaller than $\epsilon$ for agents whose initial state is $\eta=s$, and about $30 \%$ smaller for the agents whose initial state is $\eta=u$. Therefore, agents face less earnings risk in an economy without business cycles. The other individual random variables, $\eta$ and $\beta$, are independent of the aggregate shocks, and therefore their processes are unchanged after the elimination of business cycles.

\footnotetext{
${ }^{16}$ This example follows Lucas (2003).
} 


\subsection{Competitive Equilibrium}

The equilibrium after removing business cycles does not have a recursive structure for two reasons. First, the evolution of aggregate capital $\bar{k}$ and aggregate labor $\bar{n}$ (both are now deterministic) is time-dependent. Second, to calculate $\hat{y}$ at each time period, the entire history of idiosyncratic shocks has to be taken into account. ${ }^{17}$ The competitive equilibrium of this economy can be defined in the standard way-consumers and firms optimize given prices, and the markets for capital and labor clear. See Appendix A for the formal definition.

We employ three approximations to reduce the computational burden. First, since $\bar{n}$ converges to a constant value fairly quickly, we treat $\bar{n}$ as a constant after a sufficient number of periods. Second, we reduce the evolution of $\bar{k}$ to a single law of motion after a sufficient number of periods. Third, we approximate the stochastic process of $\hat{y}$ by a five-point Markov process. These approximations serve to reduce the computational time dramatically, while providing a fairly accurate approximation of the original economy.

\subsection{Results}

Our experiment is to eliminate business cycles at a specific point from the fluctuating economy. ${ }^{18}$ The timing of this "elimination" (call it time 0) is selected according to a specific level of capital stock and aggregate shocks. It is natural to select a capital stock level around the average of the fluctuating economy. Therefore, we choose $\bar{k}=144$. In the following, we pick two timings, $z=g$ and $z=b$, and compare the results.

After time 0, the economy experiences the transition to a non-fluctuating steady state. We compare the welfare of each agent at time 0, taking this transition into account. The

\footnotetext{
${ }^{17}$ In Appendix C, it is shown that the necessary information about the history of the idiosyncratic shocks can be summarized by two state variables. However, the evolution of those variables is also time-dependent.

${ }^{18}$ The algorithm used for the computation can be found in Appendix D.
} 
welfare cost from business cycles is defined (following Lucas) as $\lambda$ which satisfies

$$
E_{0}\left[\sum_{t=0}^{\infty}\left(\prod_{j=0}^{t} \beta_{j}\right) U\left((1+\lambda) c_{t}^{o}\right)\right]=E_{0}\left[\sum_{t=0}^{\infty}\left(\prod_{j=0}^{t} \beta_{j}\right) U\left(c_{t}^{s}\right)\right],
$$

where $\left\{c_{t}^{o}\right\}_{t=0}^{\infty}$ is the consumption stream in the "original" economy (with business cycles), and $\left\{c_{t}^{s}\right\}_{t=0}^{\infty}$ is the consumption stream in the "smoothed" economy (without business cycles).

For logarithmic utility, we can show that

$$
\lambda=\exp \left[\left(V_{s}-V_{o}\right) / B\right]-1
$$

where $V_{o} \equiv E_{0}\left[\sum_{t=0}^{\infty}\left(\prod_{j=0}^{t} \beta_{j}\right) U\left(c_{t}^{o}\right)\right]$ is the expected (average) discounted utility under the original economy, $V_{s} \equiv E_{0}\left[\sum_{t=0}^{\infty}\left(\prod_{j=0}^{t} \beta_{j}\right) U\left(c_{t}^{s}\right)\right]$ is the expected (average) discounted utility under the smoothed economy, and $B \equiv E_{0}\left[\sum_{t=0}^{\infty}\left(\prod_{j=0}^{t} \beta_{j}\right)\right]$.

First, consider the case where we remove the business cycles when $\bar{k}=144$ and $z=g$. The transition of aggregate capital is depicted in Figure 3. Capital stock initially increases (since $z$ is still larger than one for a while), then declines until $\bar{k}=143.4$ and slowly converges to a new steady state with $\bar{k}=143.8$, which is slightly lower than the average value in the fluctuating economy. (Figure 3 also depicts the capital stock of the fluctuating economy as a dotted line.) Krusell and Smith (2002) similarly observed a lower steady-state level of capital. They argued that the reason is because individuals have less incentive to save for precautionary motives, due to the lower risk in their income. The fact that the capital stock is lower during the most of the transition and at the new steady-state has an important implication for the welfare comparison. From the fact that $w=(1-\alpha) z \bar{k}^{\alpha} \bar{n}^{-\alpha}$ and $r=\alpha z \bar{k}^{\alpha-1} \bar{n}^{1-\alpha}$, a lower $\bar{k}$ increases $r$ and decreases $w$. Depending on whether a particular agent relies on wage income or capital income, this change will affect the agents differently.

In the new steady state, the Gini coefficient increases to 0.82 . Inequality increases within both the unskilled and skilled groups: Gini coefficients rise from 0.85 to 0.88 and from 0.73 to 0.76, respectively. This is consistent with Krusell and Smith's (2002) argument that there is less precautionary saving in the new steady-state. With less precautionary saving, the 


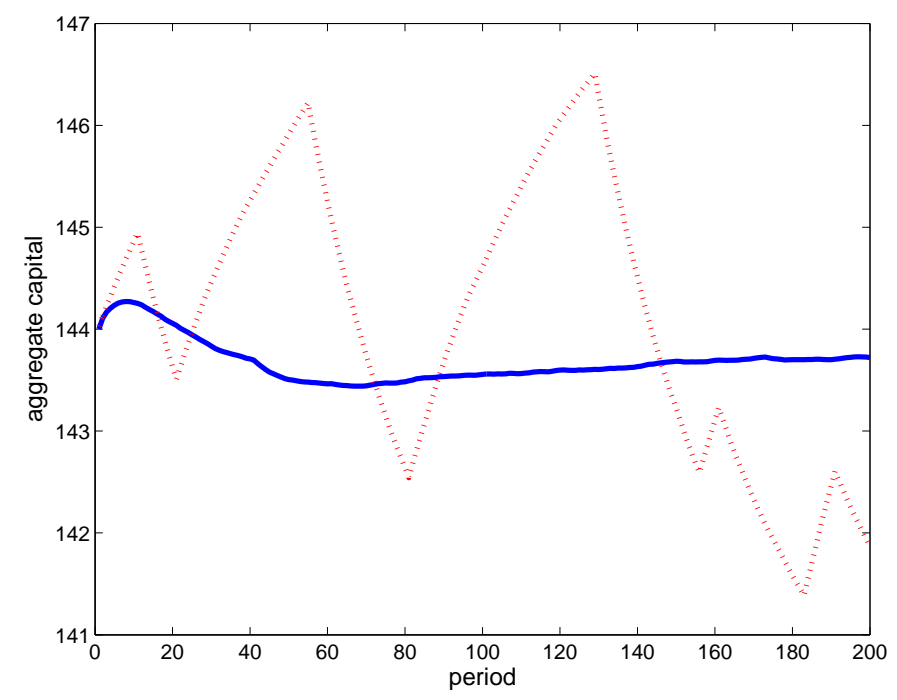

Figure 3: Path of Aggregate Capital after Removing Business Cycles with $\bar{k}=144$ and $z=g$

left tail of the distribution is extended. In fact, the number of agents with negative assets increases to $14.0 \%$ in total ( $24.5 \%$ for unskilled and $3.5 \%$ for skilled), which is almost double compared to the fluctuating economy.

Our main goal is to compare the welfare between the two economies. We follow the method described above and calculate the value of $\lambda$ for each agent. The average value of $\lambda$ is $0.024 \%$, which is more than three times larger than Lucas's (1987) result, and is comparable to the numbers found in previous studies by Atkeson and Phelan (1994) and Krusell and Smith (2002). There is a large heterogeneity between skill levels: unskilled agents gain $0.043 \%$ from the elimination of business cycles, while skilled gain only $0.005 \%$. Therefore, the gain for unskilled agents, who are more frequently unemployed and more likely to face binding borrowing constraints, is much larger than the gain suggested by the average value of $\lambda$. As a result of stabilization, $85.3 \%$ of unskilled workers have increased utility, while the fraction of skilled workers with a positive gain is much smaller at $33.7 \%$. In fact, the majority of skilled workers experience lower utility after stabilization. Two effects produce the difference in the cost of business cycles between skilled and unskilled workers. First, a 


\begin{tabular}{|l||c|c|c|c|c|c|}
\hline \multicolumn{1}{|c||}{} & \multicolumn{5}{c|}{ asset level (in total wealth distribution) } \\
\cline { 2 - 7 } & constrained & bottom $1 \%$ & $10 \%$ & $50 \%$ & $90 \%$ & $99 \%$ \\
\hline \hline$\eta=u, \epsilon=0$ & $0.150 \%$ & $0.065 \%$ & $0.026 \%$ & $-0.027 \%$ & $-0.067 \%$ & $0.133 \%$ \\
\hline$\eta=u, \epsilon=1$ & $0.117 \%$ & $0.090 \%$ & $0.068 \%$ & $0.021 \%$ & $-0.036 \%$ & $0.153 \%$ \\
\hline$\eta=s, \epsilon=0$ & $0.053 \%$ & $-0.008 \%$ & $-0.043 \%$ & $-0.083 \%$ & $-0.041 \%$ & $0.112 \%$ \\
\hline$\eta=s, \epsilon=1$ & $0.027 \%$ & $0.015 \%$ & $-0.004 \%$ & $-0.013 \%$ & $0.011 \%$ & $0.143 \%$ \\
\hline
\end{tabular}

Table 1a: The values of $\lambda$ for $\beta=0.995, \bar{k}=144$, and $z=g$

\begin{tabular}{|l||c|c|c|c|c|c|}
\hline \multicolumn{1}{|c|}{} & \multicolumn{5}{c|}{ asset level (in total wealth distribution) } \\
\cline { 2 - 7 } & constrained & bottom $1 \%$ & $10 \%$ & $50 \%$ & $90 \%$ & $99 \%$ \\
\hline \hline$\eta=u, \epsilon=0$ & $0.622 \%$ & $0.373 \%$ & $0.258 \%$ & $0.138 \%$ & $0.074 \%$ & $0.300 \%$ \\
\hline$\eta=u, \epsilon=1$ & $0.222 \%$ & $0.168 \%$ & $0.131 \%$ & $0.066 \%$ & $0.035 \%$ & $0.286 \%$ \\
\hline$\eta=s, \epsilon=0$ & $0.476 \%$ & $0.297 \%$ & $0.191 \%$ & $0.081 \%$ & $0.120 \%$ & $0.292 \%$ \\
\hline$\eta=s, \epsilon=1$ & $0.063 \%$ & $0.041 \%$ & $0.024 \%$ & $-0.002 \%$ & $0.069 \%$ & $0.267 \%$ \\
\hline
\end{tabular}

Table 1b: The values of $\lambda$ for $\beta=0.995, \bar{k}=144$, and $z=b$

majority of the skilled agents have already accumulated enough wealth to insure themselves against the idiosyncratic risk. Unskilled workers tend to gain more since their level of wealth is lower on average. Second, at an individual level, the unskilled agents were facing larger unemployment risk under business cycle fluctuations. (There is also the general equilibrium effect, whose direction is ambiguous. This effect is discussed below.)

The costs at an individual level are shown in Table 1a. We focus on the agents with $\beta=0.995 .{ }^{19}$ We observe even larger heterogeneity at an individual level. For example, for a wealth-constrained agent with $\eta=u$ (unskilled) and $\epsilon=0$ (unemployed), the cost is more than six times the average. (These are the agents whose cost is the highest.) This figure, $0.150 \%$, is nearly twenty times larger than the number obtained by Lucas (1987).

\footnotetext{
${ }^{19}$ Heterogeneity of costs across different $\beta$ is discussed in detail by Krusell and Smith (2002). It would be an interesting exercise to incorporate different forms of uninsurable idiosyncratic shocks, such as one's spouse's health or employment status. Clearly, this will add more dimensions to the heterogeneity in the economy. Unfortunately, it is not computationally straightforward to incorporate these shocks into our current model, since it will increase the number of state variables in the dynamic programming problem of the individuals.
} 


\begin{tabular}{|c|c|c|c|c|c|}
\hline & $\operatorname{Avg} \lambda$ & $\operatorname{Avg} \lambda$ for $\eta=u$ & $\operatorname{Avg} \lambda$ for $\eta=s$ & $\%$ of $u$ gaining & $\%$ of $s$ gaining \\
\hline \hline$z=g$ & $0.024 \%$ & $0.043 \%$ & $0.005 \%$ & $85.3 \%$ & $33.7 \%$ \\
\hline$z=b$ & $0.081 \%$ & $0.119 \%$ & $0.043 \%$ & $100.0 \%$ & $56.3 \%$ \\
\hline
\end{tabular}

Table 2: Average gains from different starting points

Next, consider the case where business cycles are eliminated when the aggregate state $z$ is $b$. After the elimination of business cycles, the economy moves toward the same steady state as before. The average value of $\lambda$ is higher in this case - it is $0.081 \%$ now. Again, unskilled workers gain more $(0.119 \%$ on average) than skilled workers ( $0.043 \%$ on average) The ratio of the skilled workers who experience a positive gain is now $56.3 \%$, while almost all the unskilled workers experience a positive gain. The comparison between $z=g$ and $z=b$ is summarized in Table 2 .

The individual costs are summarized in Table 1b. In every cell, the value of $\lambda$ is larger than in Table 1a. The largest gain comes from the constrained agent with $\eta=u$ and $\epsilon=0$. The largest gain, $0.622 \%$, is almost eighty times larger than what is found in Lucas (1987). ${ }^{20}$

When considering the welfare effect on individuals, two factors have to be taken into account. First, the direct effect of the risk reduction, and second, the general equilibrium effect. The first is straightforward. When business cycles are eliminated, the aggregate shocks are completely smoothed out (the interest rate and the wage become deterministic variables), and the idiosyncratic employment risk is reduced. This benefits all agents, especially the agents who cannot self-insure by their own savings. The second effect calls for a more careful analysis. Since the capital stock is lower after eliminating business cycles, on average, the interest rate rises and the wage falls. This benefits an agent for whom capital income is more

\footnotetext{
${ }^{20}$ This is somewhat smaller than the figure obtained in Krusell and Smith (2002). There are two factors that reduce our numbers compared to theirs. First, in our calibration, the average duration of unemployment is substantially shorter than Krusell and Smith's. Second, our borrowing constraint is tighter, therefore the "constrained agents" here are not as wealth-poor as Krusell and Smith's. Indeed, when we calibrate our model in a similar manner as Krusell and Smith, the largest gain for the unskilled workers increases to $1.807 \%$ (the largest gain for the skilled workers is $1.427 \%$ ). See Appendix E for details.
} 
important than wage income.

Keeping the employment status and skill status constant (within each rows of Table 1a and Table 1b), the gains from eliminating business cycles exhibit a "U-shape" pattern. ${ }^{21}$ Borrowing-constrained agents have a larger gain, reflecting the fact that they cannot selfinsure their risk by their own assets. The direct effect of the reduction in the idiosyncratic risk is very large for these agents. The "middle class" tends to have small or negative gains. For these agents, the benefit from the reduction in the idiosyncratic risk is small, since they have enough assets to insure themselves. In this case, the general equilibrium effect dominates. The middle-class agents whose income is largely coming from wage may experience lower welfare due to the wage loss. Very rich agents realize welfare gains since their income is largely coming from capital income.

Keeping the wealth level constant (within each columns of Table 1a and Table 1b), we cannot always determine whether unemployed agents gain more than employed agents, or if unskilled agents gain more than skilled agents, due to the presence of the general equilibrium effect. For borrowing-constrained agents, the direct effect of the risk reduction tends to dominate. For agents who are not constrained, the direct effect is smaller and the general equilibrium effect is more pronounced. The general equilibrium effect works in an ambiguous fashion. Given the wealth level, wage income is more important for the employed agents than for the unemployed agents, simply because the employed agents earn higher wages. Thus unemployed agents should gain more from the general equilibrium effect. In the future however, the wealth level is not given. Given the current wealth level, the future wealth level is higher for the employed agents. Therefore, employed workers benefit more from the higher interest rate in future. The relative level of this current and future effect determines who will gain more from eliminating business cycles. This same logic is applied to the relationship between the skilled agents and the unskilled agents.

\footnotetext{
${ }^{21}$ This pattern is also observed in Krusell and Smith (2002). We observe some non-monotonicity after $99 \%$.
} 


\section{Conclusion}

In this paper we calculated the costs of business cycles for different groups of people under incomplete markets. We focused primarily on the difference in skills. Unskilled agents face more cyclical unemployment risk and have less opportunity to self-insure. As a result, the cost of business cycles is much larger for a typical unskilled agent compared to a typical skilled agent. If business cycles are eliminated at booms, unskilled agents gain 0.043\% (of steady-state consumption) on average, while skilled workers gain only $0.005 \%$. If business cycles are eliminated in recessions, unskilled agents gain $0.119 \%$ on average, while skilled workers gain $0.043 \%$. In this case, borrowing-constrained, unskilled, and unemployed agents gain as much as $0.622 \%$, which is nearly eighty times larger than the number found using the representative-agent framework.

This substantial heterogeneity raises natural questions about optimal policy. How should the stabilization policy be conducted? Is it possible for the government to transfer risks from unskilled to skilled workers instead of stabilizing the economy? Is there an optimal mix of stabilization policy and insurance policy? These are important questions for future research. ${ }^{22}$ The difference in costs also has an important implication in the political process. It is likely that the majority of unskilled agents favor a stabilization policy (if it comes with a small cost), while many skilled agents may vote against such a policy, if the burden falls evenly on different groups. A policy that directly transfers cyclical risk from unskilled to skilled workers may be politically more agreeable. To analyze such possibilities, incorporating specific policies and political processes into an incomplete markets setting seems to be a promising future research topic.

\footnotetext{
${ }^{22}$ See Lucas (2003) for related points.
} 


\section{Appendix}

\section{A Formal Definitions of Equilibrium}

\section{A.1 Recursive Competitive Equilibrium for the Economy with Fluctua- tions}

Definition 1 (Recursive Competitive Equilibrium) The recursive competitive equilibrium consists of the value function $v(k, \epsilon, \eta, \beta ; z, \Gamma)$, a set of decision rules for consumption and asset holdings $\left\{c(k, \epsilon, \eta, \beta ; z, \Gamma), k^{\prime}(k, \epsilon, \eta, \beta ; z, \Gamma)\right\}$, aggregate capital and labor $\{\bar{k}(z, \Gamma), \bar{n}(z, \Gamma)\}$, factor prices $\{w(z, \Gamma), r(z, \Gamma)\}$, and a law of motion for the distribution, $\Gamma^{\prime}=\mathbf{T}\left(\Gamma, z, z^{\prime}\right)$, which satisfy

1. Given the aggregate states, $\{z, \Gamma\}$, prices $\{w(z, \Gamma), r(z, \Gamma)\}$, and the law of motion for the distribution, $\Gamma^{\prime}=\mathbf{T}\left(\Gamma, z, z^{\prime}\right)$; the value function $v(k, \epsilon, \eta, \beta ; z, \Gamma)$ and the individual decision rules $\left\{c(k, \epsilon, \eta, \beta ; z, \Gamma), k^{\prime}(k, \epsilon, \eta, \beta ; z, \Gamma)\right\}$ solve the following dynamic programming problem:

$$
v(k, \epsilon, \eta, \beta ; z, \Gamma)=\max _{c, k^{\prime}}\left\{\log c+\beta E\left[v\left(k^{\prime}, \epsilon^{\prime}, \eta^{\prime}, \beta^{\prime} ; z^{\prime}, \Gamma^{\prime}\right) \mid \epsilon, \eta, \beta, z, \Gamma\right]\right\}
$$

subject to

$$
\begin{gathered}
c+k^{\prime}=r(z, \Gamma) k+w(z, \Gamma) \phi(\eta) \theta(\epsilon)+(1-\delta) k, \\
k^{\prime} \geq \underline{k},
\end{gathered}
$$

and

$$
\Gamma^{\prime}=\mathbf{T}\left(\Gamma, z, z^{\prime}\right)
$$

2. Firms optimize:

$$
\begin{gathered}
w(z, \Gamma)=(1-\alpha) z \bar{k}^{\alpha} \bar{n}^{-\alpha}, \\
r(z, \Gamma)=\alpha z \bar{k}^{\alpha-1} \bar{n}^{1-\alpha} .
\end{gathered}
$$


3. Markets clear:

$$
\begin{gathered}
\bar{k}=\int k d \Gamma, \\
\bar{n}=\int \phi(\eta) \theta(\epsilon) d \Gamma .
\end{gathered}
$$

4. Consistency:

$$
\Gamma^{\prime}(K, E, X, B)=\int_{K, E, X, B}\left[\int_{\mathcal{K}, \mathcal{E}, \mathcal{X}, \mathcal{B}} \mathcal{I}_{\left\{k^{\prime}=k^{\prime}(k, \epsilon, \eta, \beta ; z, \Gamma)\right\}} \pi_{\epsilon \epsilon^{\prime}}^{z \eta^{\prime} \eta^{\prime}} q_{\eta \eta^{\prime}} \omega_{\beta \beta^{\prime}} d \Gamma\right] d k^{\prime} d \epsilon^{\prime} d \eta^{\prime} d \beta^{\prime}
$$

for all $K \subset \mathcal{K}, E \subset \mathcal{E}, X \subset \mathcal{X}$, and $B \subset \mathcal{B} . \mathcal{K}, \mathcal{E}, \mathcal{X}$, and $\mathcal{B}$ are the sets of all possible realizations of $k, \epsilon, \eta$, and $\beta$, respectively. The indicator function $\mathcal{I}_{\{\cdot\}}$ takes the value 1 if the statement is true, and 0 if it is false. $\pi_{\epsilon \epsilon^{\prime}}^{z \eta^{\prime} \eta^{\prime}}, q_{\eta \eta^{\prime}}$, and $\omega_{\beta \beta^{\prime}}$ are the transition probabilities.

\section{A.2 Competitive Equilibrium for the Economy without Fluctuations}

Definition 2 (Competitive Equilibrium without Aggregate Shocks) Let time 0 be the moment when the business cycles are removed. Denote the history of idiosyncratic shocks for an agent $j$ by $h_{j}^{t}$. The competitive equilibrium consists of individual decision rules for consumption and the next period capital $\left\{c_{t}\left(h_{j}^{t}\right), k_{t+1}\left(h_{j}^{t}\right)\right\}$, factor prices $\left\{w_{t}, r_{t}\right\}$, and the aggregate variables $\left\{\bar{k}_{t}, \bar{n}_{t}\right\}$ that satisfy

1. Given $\left\{w_{t}, r_{t}\right\}$, consumers optimize:

$$
E_{0} \sum_{t=0}^{\infty}\left(\prod_{j=0}^{t} \beta_{j}\right) \log c_{t},
$$

with $\beta_{0}=1$, subject to

$$
\begin{gathered}
c_{t}+k_{t+1}=r_{t} k_{t}+w_{t} \phi\left(\eta_{t}\right) \hat{y}_{t}+(1-\delta) k_{t}, \\
k_{t+1} \geq \underline{k} .
\end{gathered}
$$


2. Firms optimize:

$$
\begin{gathered}
w_{t}=(1-\alpha) \bar{k}_{t}^{\alpha} \bar{n}_{t}^{-\alpha}, \\
r_{t}=\alpha \bar{k}_{t}^{\alpha-1} \bar{n}_{t}^{1-\alpha} .
\end{gathered}
$$

3. Markets clear:

$$
\bar{k}_{t}=\int_{J} k_{t, j} d j
$$

where $k_{t, j}$ is the asset holding of an agent $j$ at time $t$,

$$
\bar{n}=\int \phi\left(\eta_{t}\right) \hat{y}_{t} d \Gamma_{t}
$$

where $\Gamma_{t}$ is the measure over $\eta_{t}$ and $\hat{y}_{t}$.

\section{B Calibration}

In the following, we discuss how we calibrate the parameters and stochastic processes in detail.

\section{Aggregate Shocks}

Aggregate shocks take the values $z \in\{b, g\}=\{0.99,1.01\}$. The transition matrix is:

$$
\left[\begin{array}{ll}
p_{b b} & p_{b g} \\
p_{g b} & p_{g g}
\end{array}\right]
$$

where $p_{i j}$ is the probability of the transition from state $i$ to state $j$. Following Krusell and Smith $(1999,2002)$ we set the average business cycle duration to 2 years. Our model period is six weeks, therefore the average duration is 16 periods. From $1 /\left(1-p_{b b}\right)=1 /\left(1-p_{g g}\right)=16$, $p_{b b}=p_{g g}=0.9375$, so

$$
\left[\begin{array}{ll}
p_{b b} & p_{b g} \\
p_{g b} & p_{g g}
\end{array}\right]=\left[\begin{array}{ll}
0.9375 & 0.0625 \\
0.0625 & 0.9375
\end{array}\right] .
$$

The invariant distribution is $\left[\begin{array}{ll}0.5 & 0.5\end{array}\right]$.

\section{Skill Transition}


For each generation, the transition probability from skilled (college graduate) to skilled is 0.65 , and the transition probabilty from unskilled (high school graduate) to skilled is 0.35 . The transition matrix satisfies ${ }^{23}$

$$
\left[\begin{array}{ll}
q_{u u} & q_{u s} \\
q_{s u} & q_{s s}
\end{array}\right]^{240}=\left[\begin{array}{ll}
0.65 & 0.35 \\
0.35 & 0.65
\end{array}\right] .
$$

This provides

$$
\left[\begin{array}{ll}
q_{u u} & q_{u s} \\
q_{s u} & q_{s s}
\end{array}\right]=\left[\begin{array}{ll}
0.9975 & 0.0025 \\
0.0025 & 0.9975
\end{array}\right] .
$$

The invariant distribution is

$$
\left[\begin{array}{ll}
\chi_{u} & \chi_{s}
\end{array}\right]=\left[\begin{array}{ll}
0.5 & 0.5
\end{array}\right]
$$

Note that if we start from the invariant distribution, the fraction of skilled workers remains constant by the law of large numbers.

\section{Individual Employment Shocks}

For individual employment shocks $\epsilon \in\{0,1\}$, the transition matrix has to be conditioned on last period's aggregate state $(z)$, today's aggregate state $\left(z^{\prime}\right)$, and today's skill level $\left(\eta^{\prime}\right)$. Denote this matrix as $\Pi^{z z^{\prime} \eta^{\prime}}$. Here, we illustrate the case of $z=b, z^{\prime}=b$, and $\eta^{\prime}=u$.

$$
\Pi^{b b u}=\left[\begin{array}{ll}
\pi_{00}^{b b u} & \pi_{01}^{b b u} \\
\pi_{10}^{b b u} & \pi_{11}^{b b u}
\end{array}\right] .
$$

The unemployment rate of skill level $\eta$ when the aggregate state is $z$ is denoted as $\mu_{\eta}^{z}$. We calibrate $\mu_{\eta}^{z}$ from the Current Population Survey. Each year between 1970 to 2001 is divided into two categories (with an equal number of good and bad years) by ranking the years according to the total unemployment rate. $\mu_{\eta}^{z}$ is given as the average unemployment rate of

\footnotetext{
${ }^{23}$ Mayer (2002, Table 1) shows that in PSID data, the intergenerational transition probability (between fathers and sons) from no-college to college is 35\%, while college to college is $73 \%$. Statistics Canada (1998, p.37) compares the intergenerational transition of schooling attainment across countries. It shows that in the United States, $64.2 \%$ of the population attains postsecondary schooling if their parents attained postsecondary education. If the parents attain only secondary education, the percentage drops to $35.7 \%$.
} 
the skilled and the unskilled for the good and the bad years. ${ }^{24}$

The number of people who were unskilled and unemployed in the last period is $\chi_{u} \mu_{u}^{b}$. They remain unskilled in the current period with probability $q_{u u}$. Thus, the number of people who were unskilled and unemployed in the last period, and remain unskilled in the current period is $\chi_{u} \mu_{u}^{b} q_{u u}$. The amount of people who were skilled and unemployed in the last period is $\chi_{s} \mu_{s}^{b}$. They become unskilled in the current period with probability $q_{s u}$. Thus, the amount of people who were skilled and unemployed in the last period, and become unskilled in the current period is $\chi_{s} \mu_{s}^{b} q_{s u}$. Summing up, the people who were unemployed in the last period and unskilled in the current period is $\chi_{u} \mu_{u}^{b} q_{u u}+\chi_{s} \mu_{s}^{b} q_{s u}$. The people who were employed in the last period and unskilled in the current period is $\chi_{u}\left(1-\mu_{u}^{b}\right) q_{u u}+\chi_{s}\left(1-\mu_{s}^{b}\right) q_{s u}$. Thus, as the transition occurs

$$
\begin{gathered}
{\left[\begin{array}{cc}
\chi_{u} \mu_{u}^{b} q_{u u}+\chi_{s} \mu_{s}^{b} q_{s u} & \chi_{u}\left(1-\mu_{u}^{b}\right) q_{u u}+\chi_{s}\left(1-\mu_{s}^{b}\right) q_{s u}
\end{array}\right]\left[\begin{array}{cc}
\pi_{00}^{b b u} & \pi_{01}^{b b u} \\
\pi_{10}^{b b u} & \pi_{11}^{b b u}
\end{array}\right]} \\
=\left[\begin{array}{l}
\pi_{00}^{b b u} \chi_{u} \mu_{u}^{b} q_{u u}+\pi_{00}^{b b u} \chi_{s} \mu_{s}^{b} q_{s u}+\pi_{10}^{b b u} \chi_{u}\left(1-\mu_{u}^{b}\right) q_{u u}+\pi_{10}^{b b u} \chi_{s}\left(1-\mu_{s}^{b}\right) q_{s u} \\
\pi_{01}^{b b u} \chi_{u} \mu_{u}^{b} q_{u u}+\pi_{01}^{b b u} \chi_{s} \mu_{s}^{b} q_{s u}+\pi_{11}^{b b u} \chi_{u}\left(1-\mu_{u}^{b}\right) q_{u u}+\pi_{11}^{b b u} \chi_{s}\left(1-\mu_{s}^{b}\right) q_{s u}
\end{array}\right] .
\end{gathered}
$$

Since the current period is a bad state, the first entry has to be equal to $\chi_{u} \mu_{u}^{b}$. This provides us with the first restriction. (The second entry has to be equal to $\chi_{u}\left(1-\mu_{u}^{b}\right)$, but it is easy to show that this is automatically satisfied by the first restriction, provided that $\chi$ is the invariant distribution.) Now we have two unknowns, $\pi_{00}^{b b u}$ and $\pi_{10}^{b b u}$, and one equation (the other unknowns are determined by the condition that the probabilities sum up to one: $\pi_{00}^{b b u}+\pi_{01}^{b b u}=$ 1 and $\left.\pi_{10}^{b b u}+\pi_{11}^{b b u}=1\right)$. Another restriction is provided from the unemployment duration data. The Current Population Survey provides the average duration of unemployment in each year. We calculated the average duration in the good years and in the bad years (defined by the total unemployment rate), and obtained that the duration is 12.4 weeks for good years

\footnotetext{
${ }^{24}$ The skilled are defined as individuals with some college or college completion, and the unskilled are defined as those with high school completion or less. Since the population of each group changes over time, we have taken the weighted average of the unemployment rates in each group using the number of individuals aged 24 and up (the population is taken from the census data) at each year.
} 
and 15.9 weeks for bad years. ${ }^{25}$ Mincer (1991) shows (using PSID data) that the average duration of unemployment is not significantly different between skilled and unskilled workers, and therefore we use the same numbers for the skilled and the unskilled. The restriction is $1 /\left(1-\pi_{00}^{b b u}\right)=15.9 / 6$. When selecting $\pi_{00}^{b g \eta^{\prime}}$ and $\pi_{00}^{g b \eta^{\prime}}$, there exist two approachs:

1. $\pi_{00}^{b g \eta^{\prime}}=\pi_{00}^{g g \eta^{\prime}}$ and $\pi_{00}^{g b \eta^{\prime}}=\pi_{00}^{b b \eta^{\prime}}$ (İmrohoroğlu [1989])

2. $\pi_{00}^{b g \eta^{\prime}}=0.75 \cdot \pi_{00}^{g g \eta^{\prime}}$ and $\pi_{00}^{g b \eta^{\prime}}=1.25 \cdot \pi_{00}^{b b \eta^{\prime}}$ (Krusell and Smith [1999, 2002]).

We follow Krusell and Smith.

From the data on unemployment between 1970 and 2001 (described above), we calculate $\mu_{u}^{b}=0.087, \mu_{u}^{g}=0.056, \mu_{s}^{b}=0.038$, and $\mu_{s}^{g}=0.026$.

Given above numbers, $\pi_{10}^{b b u}$ is derived from

$$
\pi_{10}^{b b u}=\frac{\chi_{u} \mu_{u}^{b}-\pi_{00}^{b b u}\left(\chi_{u} \mu_{u}^{b} q_{u u}+\chi_{s} \mu_{s}^{b} q_{s u}\right)}{\chi_{u}\left(1-\mu_{u}^{b}\right) q_{u u}+\chi_{s}\left(1-\mu_{s}^{b}\right) q_{s u}}
$$

In general, $\pi_{10}^{z z^{\prime} \eta^{\prime}}$ is derived from

$$
\pi_{10}^{z z^{\prime} \eta^{\prime}}=\frac{\chi_{\eta^{\prime}} \mu_{\eta^{\prime}}^{z^{\prime}}-\pi_{00}^{z z^{\prime} \eta^{\prime}}\left(\chi_{u} \mu_{u}^{z} q_{u \eta^{\prime}}+\chi_{s} \mu_{s}^{z} q_{s \eta^{\prime}}\right)}{\chi_{u}\left(1-\mu_{u}^{z}\right) q_{u \eta^{\prime}}+\chi_{s}\left(1-\mu_{s}^{z}\right) q_{s \eta^{\prime}}} .
$$

The resulting $\Pi$ matrices are:

$$
\begin{aligned}
\Pi^{b b u} & =\left[\begin{array}{ll}
0.6226 & 0.3774 \\
0.0383 & 0.9617
\end{array}\right], \\
\Pi^{g b u} & =\left[\begin{array}{ll}
0.7783 & 0.2217 \\
0.0483 & 0.9517
\end{array}\right], \\
\Pi^{b g u} & =\left[\begin{array}{ll}
0.3871 & 0.6129 \\
0.0269 & 0.9731
\end{array}\right], \\
\Pi^{g g u} & =\left[\begin{array}{ll}
0.5161 & 0.4839 \\
0.0309 & 0.9691
\end{array}\right],
\end{aligned}
$$

\footnotetext{
${ }^{25}$ Imrohoroğlu (1989) uses the duration of 10 weeks in good times and 14 weeks in bad times. Krusell and Smith $(1999,2002)$ use 19.5 weeks and 32.5 weeks.
} 


$$
\begin{aligned}
\Pi^{b b s} & =\left[\begin{array}{ll}
0.6226 & 0.3774 \\
0.0152 & 0.9848
\end{array}\right], \\
\Pi^{g b s} & =\left[\begin{array}{ll}
0.7783 & 0.2217 \\
0.0184 & 0.9758
\end{array}\right], \\
\Pi^{\text {bgs }} & =\left[\begin{array}{ll}
0.3871 & 0.6129 \\
0.0123 & 0.9877
\end{array}\right], \\
\Pi^{g g s} & =\left[\begin{array}{ll}
0.5161 & 0.4839 \\
0.0134 & 0.9866
\end{array}\right] .
\end{aligned}
$$

\section{Stochastic $\beta$}

Following Krusell and Smith (1998), we assume that the discount factor $\beta_{t}$ follows a three-point Markov stochastic process. Let $\beta_{t} \in\left\{\beta_{l}, \beta_{m}, \beta_{h}\right\}$, where $\beta_{l}<\beta_{m}<\beta_{h}$. An agent with the discount factor $\beta=\beta_{l}$ is impatient, and an agent with the discount factor $\beta=\beta_{h}$ is patient. First, we calibrate the Markov transition matrix by imposing the following restrictions.

- $10 \%$ of the total population has $\beta=\beta_{l}, 80 \%$ of the population has $\beta=\beta_{m}$, and $10 \%$ of the population has $\beta=\beta_{h}$.

- There is no direct transition in between $\beta=\beta_{l}$ and $\beta=\beta_{h}$.

- The average duration of the extreme states, $\beta=\beta_{l}$ and $\beta=\beta_{h}$, is one generation (30 years).

The transition probabilities from state $\beta_{i}$ to state $\beta_{j}, \omega_{i j}$ are

$$
\left[\begin{array}{ccc}
\omega_{l l} & \omega_{l m} & \omega_{l h} \\
\omega_{m l} & \omega_{m m} & \omega_{m h} \\
\omega_{h l} & \omega_{h m} & \omega_{h h}
\end{array}\right]=\left[\begin{array}{ccc}
239 / 240 & 1 / 240 & 0 \\
1 / 1920 & 959 / 960 & 1 / 1920 \\
0 & 1 / 240 & 239 / 240
\end{array}\right] .
$$

Second, the values of $\beta_{l}, \beta_{m}, \beta_{h}$ are pinned down so that the resulting distribution of asset holdings mimics the real wealth distribution. In particular, $\beta_{l}=0.9923, \beta_{m}=0.995$, and $\beta_{h}=0.9977$. 


\section{Applying the "Integration Principle" to Idiosyncratic Shocks}

Applying the "integration principle" to a two-point process is more difficult than the continuous example in the main text. Here, starting from the static case, we extend the analysis step by step. ${ }^{26}$

\section{C.1 Static Case}

Let $z$ take two values, $g$ and $b$, and $\epsilon$ take two values, 0 and 1 . The aggregate state $z$ occurs with the probability $\pi_{z}(z)$, and $\epsilon$ 's probability depends only on the current $z$. The conditional probability of $\epsilon$ given $z$ is denoted as $\pi(\epsilon \mid z)$. We define $i \sim U(0,1)$, and

$$
\bar{g}(i, z)= \begin{cases}1 & \text { if } i \leq \pi(1 \mid z) \\ 0 & \text { otherwise }\end{cases}
$$

Thus, when $i \in[0, \pi(1 \mid b)]$,

$$
\hat{y}=\sum_{z} \bar{g}(i, z) \pi_{z}(z)=\bar{g}(i, g) \pi_{z}(g)+\bar{g}(i, b) \pi_{z}(b)=1 \cdot \pi_{z}(g)+1 \cdot \pi_{z}(b)=1 .
$$

When $i \in(\pi(1 \mid b), \pi(1 \mid g)]$,

$$
\hat{y}=\bar{g}(i, g) \pi_{z}(g)+\bar{g}(i, b) \pi_{z}(b)=1 \cdot \pi_{z}(g)+0 \cdot \pi_{z}(b)=\pi_{z}(g)
$$

When $i \in(\pi(1 \mid g), 1]$,

$$
\hat{y}=\bar{g}(i, g) \pi_{z}(g)+\bar{g}(i, b) \pi_{z}(b)=0 \cdot \pi_{z}(g)+0 \cdot \pi_{z}(b)=0 .
$$

In sum, $\hat{y}=1$ with probability $\pi(1 \mid b), \hat{y}=\pi_{z}(g)$ with probability $\pi(1 \mid g)-\pi(1 \mid b)$, and $\hat{y}=0$ with probability $1-\pi(1 \mid g)$.

\section{C.2 Correlation over Time}

When $z$ and $\epsilon$ are correlated over time, applying this procedure becomes more complicated. Suppose that $z$ evolves by a first-order Markov process and that $\epsilon_{t}$ depends on $z_{t}, z_{t-1}$, and

\footnotetext{
${ }^{26}$ For exposition, in this section we utilized slightly different notation than the main text. The correspondence should be clear, however.
} 
$\epsilon_{t-1}$. Let $i_{t}$ be an i.i.d. random variable which follows $U[0,1]$. We must then find a function $\bar{g}(\cdot, \cdot)$ which satisfies

$$
\bar{g}_{t}\left(\left\{i_{s}\right\}_{0}^{t},\left\{z_{s}\right\}_{0}^{t}\right)=g_{t}\left(\left\{\epsilon_{s}\right\}_{0}^{t},\left\{z_{s}\right\}_{0}^{t}\right)
$$

and then integrate $\bar{g}_{t}\left(\left\{i_{s}\right\}_{0}^{t},\left\{z_{s}\right\}_{0}^{t}\right)$ over $\left\{z_{s}\right\}_{0}^{t}$. Note that the right hand side is the employment variable, $g_{t}\left(\left\{\epsilon_{s}\right\}_{0}^{t},\left\{z_{s}\right\}_{0}^{t}\right)=\epsilon_{t}$.

\section{C.2.1 Brute-Force}

One way to do this is by brute-force simulation: generate $z_{t}$ and $i_{t}$ randomly, and then create $\epsilon_{t}$ from the realization. Iterate the simulation many times. Then, for each $\left\{i_{s}\right\}_{0}^{t}$, there will be a distribution of $\epsilon_{t}$ (depending on the realizations (history) of $z, \epsilon$ can be different for the same $\left.\left\{i_{s}\right\}_{0}^{t}\right)$. Average this out and use as the new idiosyncratic shocks at each $t$. We did not utilize this method here.

\section{C.2.2 Recursive}

Instead, we utilized the following method, which exploits the recursive structure of the problem. From the distributional assumptions, to express $\epsilon_{t}$ by an i.i.d. random variable $i_{t} \sim U(0,1)$, the additional information required is $z_{t-1}, z_{t}$, and $\epsilon_{t-1}$. That is, given $z_{t-1}, z_{t}$, and $\epsilon_{t-1}, \epsilon_{t}$ can be determined by the rule

$$
\epsilon_{t}= \begin{cases}1 & \text { if } i_{t} \leq \Omega\left(z_{t-1}, z_{t}, \epsilon_{t-1}\right) \\ 0 & \text { otherwise }\end{cases}
$$

where $\Omega\left(z_{t-1}, z_{t}, \epsilon_{t-1}\right)$ is the threshold value calculated from the original Markov transition matrices. However, we can not integrate this yet. $\Omega\left(z_{t-1}, z_{t}, \epsilon_{t-1}\right)$ still depends on $\epsilon_{t-1}$. To construct the $\bar{g}_{t}(\cdot, \cdot)$ function, we still require $\epsilon_{t-1}$ to be expressed by $i$ and $z$. By working from $t=0$ using (3) ( $\epsilon_{-1}$ is given), we can express $\epsilon_{t-1}$ by $\left\{\left\{i_{s}\right\}_{0}^{t-1},\left\{z_{s}\right\}_{0}^{t-1}\right\}$. Clearly, this procedure has recursive structure.

Equation (2) can be expressed as $\bar{g}_{t}\left(i_{t}, z_{t}, z_{t-1}, \epsilon_{t-1}\right)=\epsilon_{t}$, where $\epsilon_{t-1}$ on the left hand side is actually a function of $\left\{\left\{i_{s}\right\}_{0}^{t-1},\left\{z_{s}\right\}_{0}^{t-1}\right\}$. The integration principle requires us to calculate, 
for each $\left\{i_{s}\right\}_{0}^{t}$,

$$
\hat{y}_{t}=\sum_{z_{t}} \cdots \sum_{z_{0}} \bar{g}_{t}\left(i_{t}, z_{t}, z_{t-1}, \epsilon_{t-1}\right) \cdot \pi_{z}\left(z_{t}, \ldots, z_{0}\right)
$$

This can be rewritten as

$$
\begin{aligned}
\hat{y}_{t}= & \sum_{z_{t-1}} \cdots \sum_{z_{0}} \bar{g}_{t}\left(i_{t}, g, z_{t-1}, \epsilon_{t-1}\right) \cdot \pi_{z}\left(g, z_{t-1} \ldots, z_{0}\right) \\
& +\sum_{z_{t-1}} \cdots \sum_{z_{0}} \bar{g}_{t}\left(i_{t}, b, z_{t-1}, \epsilon_{t-1}\right) \cdot \pi_{z}\left(b, z_{t-1}, \ldots, z_{0}\right) .
\end{aligned}
$$

The first part can be rewritten as

$$
\begin{aligned}
& \sum_{z_{t-1}} \cdots \sum_{z_{0}} \bar{g}_{t}\left(i_{t}, g, z_{t-1}, \epsilon_{t-1}\right) \cdot \pi_{z}\left(g, z_{t-1} \ldots, z_{0}\right) \\
= & \sum_{z_{t-2}} \cdots \sum_{z_{0}} \bar{g}_{t}\left(i_{t}, g, g, \epsilon_{t-1}\right) \cdot \pi_{z}\left(g, g, z_{t-2} \ldots, z_{0}\right) \\
& +\sum_{z_{t-2}} \cdots \sum_{z_{0}} \bar{g}_{t}\left(i_{t}, g, b, \epsilon_{t-1}\right) \cdot \pi_{z}\left(g, b, z_{t-2} \ldots, z_{0}\right) .
\end{aligned}
$$

The second part can be expressed in a similar way.

Let $P_{t-1}(g, \epsilon)$ be the probability that, for given $\left\{i_{s}\right\}_{0}^{t-1}$, the realization of $\left\{z_{s}\right\}_{0}^{t-1}$ induces (i) $z_{t-1}=g$ and (ii) $\epsilon_{t-1}=\epsilon$.

Further, let $\pi_{z}\left(z_{t} \mid z_{t-1}\right)$ be the conditional probability. Then, the first part of (4) can be rewritten as:

$$
\begin{aligned}
& \sum_{z_{t-2}} \cdots \sum_{z_{0}} \bar{g}_{t}\left(i_{t}, g, g, \epsilon_{t-1}\right) \cdot \pi_{z}\left(g, g, z_{t-2} \ldots, z_{0}\right) \\
= & \bar{g}_{t}\left(i_{t}, g, g, 1\right) \cdot \pi_{z}(g \mid g) \cdot P_{t-1}(g, 1)+\bar{g}_{t}\left(i_{t}, g, g, 0\right) \cdot \pi_{z}(g \mid g) \cdot P_{t-1}(g, 0) .
\end{aligned}
$$

Here, $\bar{g}_{t}\left(i_{t}, g, g, 1\right)$ is either 0 or 1 , and is easy to calculate using $(3) . \pi_{z}(g \mid g)$ is given by the Markov transition matrix. Thus, given $P_{t-1}\left(z_{t-1}, \epsilon_{t-1}\right), \hat{y}_{t}$ can be calculated only from the information of $i_{t}$, using (5) for all possible combinations of $z_{t-1}$ and $z_{t}$.

How can we get $P_{t-1}\left(z_{t-1}, \epsilon_{t-1}\right)$ ? It can be calculated recursively. First, notice that $P_{t-1}\left(z_{t-1}, 0\right)+P_{t-1}\left(z_{t-1}, 1\right)=\pi_{z}\left(z_{t-1}\right)$, where $\pi_{z}\left(z_{t-1}\right)$ can be mechanically calculated from the Markov transition matrix and the initial value $z_{0}$. Thus, we only need to keep track of $P_{t-1}\left(z_{t-1}, 1\right)$. To obtain $P_{t}(g, 1)$, we have to calculate the probability of (i) $z_{t}=g$ and (ii) $\epsilon_{t}=1$. This can be done by just picking up the $z_{t}=g$ part in the $\hat{y}_{t}$ calculation (sum of 
(5) for all possible combinations of $z_{t-1}$ and $\left.z_{t}\right)$, since $\bar{g}_{t}\left(i_{t}, z_{t}, z_{t-1}, \epsilon_{t-1}\right)=1$ if $\epsilon_{t}=1$ and $\bar{g}_{t}\left(i_{t}, z_{t}, z_{t-1}, \epsilon_{t-1}\right)=0$ if $\epsilon_{t}=0$. That is,

$$
\begin{aligned}
& P_{t}(g, 1)=\bar{g}_{t}\left(i_{t}, g, g, 1\right) \cdot \pi_{z}(g \mid g) \cdot P_{t-1}(g, 1) \\
& +\bar{g}_{t}\left(i_{t}, g, g, 0\right) \cdot \pi_{z}(g \mid g) \cdot P_{t-1}(g, 0) \\
& +\bar{g}_{t}\left(i_{t}, g, b, 1\right) \cdot \pi_{z}(g \mid b) \cdot P_{t-1}(b, 1) \\
& +\bar{g}_{t}\left(i_{t}, g, b, 0\right) \cdot \pi_{z}(g \mid b) \cdot P_{t-1}(b, 0) \text {. }
\end{aligned}
$$

In the same way,

$$
\begin{aligned}
P_{t}(b, 1)= & \bar{g}_{t}\left(i_{t}, b, g, 1\right) \cdot \pi_{z}(b \mid g) \cdot P_{t-1}(g, 1) \\
+ & \bar{g}_{t}\left(i_{t}, b, g, 0\right) \cdot \pi_{z}(b \mid g) \cdot P_{t-1}(g, 0) \\
+ & \bar{g}_{t}\left(i_{t}, b, b, 1\right) \cdot \pi_{z}(b \mid b) \cdot P_{t-1}(b, 1) \\
+ & \bar{g}_{t}\left(i_{t}, b, b, 0\right) \cdot \pi_{z}(b \mid b) \cdot P_{t-1}(b, 0) .
\end{aligned}
$$

Note that

$$
\hat{y}_{t}=P_{t}(g, 1)+P_{t}(b, 1)
$$

by construction. Up to this part, our procedure follows Krusell and Smith (2002).

\section{C.3 Extending to Multiple Skill Levels}

Suppose that the employment probability is also dependent on skill level $\eta \in\{u, s\}$, which evolves stochastically. The evolution of $\eta$ is first-order Markov, and independent of $\epsilon$ and $z$. Specifically, $y_{t}\left(=\epsilon_{t}\right)$ depends on $\epsilon_{t-1}, z_{t-1}, z_{t}$, and $\eta_{t}$. Now, (3) has to be modified to ${ }^{27}$

$$
\epsilon_{t}= \begin{cases}1 & \text { if } i_{t} \leq \Omega\left(z_{t-1}, z_{t}, \epsilon_{t-1}, \eta_{t}\right), \\ 0 & \text { otherwise. }\end{cases}
$$

Here, $\epsilon_{t-1}$ depends on $\left\{\left\{i_{s}\right\}_{0}^{t-1},\left\{\eta_{s}\right\}_{0}^{t-1},\left\{z_{s}\right\}_{0}^{t-1}\right\}$. Clearly, after integration, $\hat{y}$ is a function of $\left\{\left\{i_{s}\right\}_{0}^{t},\left\{\eta_{s}\right\}_{0}^{t}\right\}$. Similar steps from the previous case apply. Given $\left\{\left\{i_{s}\right\}_{0}^{t},\left\{\eta_{s}\right\}_{0}^{t}\right\}$,

$$
\hat{y}_{t}=\sum_{z_{t}} \cdots \sum_{z_{0}} \bar{g}_{t}\left(i_{t}, z_{t}, z_{t-1}, \epsilon_{t-1}, \eta_{t}\right) \cdot \pi_{z}\left(z_{t}, \ldots, z_{0}\right)
$$

This can be rewritten as

$$
\begin{aligned}
\hat{y}_{t}= & \sum_{z_{t-1}} \cdots \sum_{z_{0}} \bar{g}_{t}\left(i_{t}, g, z_{t-1}, \epsilon_{t-1}, \eta_{t}\right) \cdot \pi_{z}\left(g, z_{t-1} \ldots, z_{0}\right) \\
& +\sum_{z_{t-1}} \cdots \sum_{z_{0}} \bar{g}_{t}\left(i_{t}, b, z_{t-1}, \epsilon_{t-1}, \eta_{t}\right) \cdot \pi_{z}\left(b, z_{t-1}, \ldots, z_{0}\right) .
\end{aligned}
$$

\footnotetext{
${ }^{27}$ Clearly, $\Omega\left(z_{t-1}, z_{t}, \epsilon_{t-1}, \eta_{t}\right)$ here should be set to $\pi_{\epsilon_{t-1} 1}^{z_{t-1} z_{t} \eta_{t}}$ in the main text.
} 
The first part can be rewritten as

$$
\begin{aligned}
& \sum_{z_{t-1}} \cdots \sum_{z_{0}} \bar{g}_{t}\left(i_{t}, g, z_{t-1}, \epsilon_{t-1}, \eta_{t}\right) \cdot \pi_{z}\left(g, z_{t-1} \ldots, z_{0}\right) \\
= & \sum_{z_{t-2}} \cdots \sum_{z_{0}} \bar{g}_{t}\left(i_{t}, g, g, \epsilon_{t-1}, \eta_{t}\right) \cdot \pi_{z}\left(g, g, z_{t-2} \ldots, z_{0}\right) \\
& +\sum_{z_{t-2}} \cdots \sum_{z_{0}} \bar{g}_{t}\left(i_{t}, g, b, \epsilon_{t-1}, \eta_{t}\right) \cdot \pi_{z}\left(g, b, z_{t-2} \ldots, z_{0}\right) .
\end{aligned}
$$

The second part can be expressed in a similar way.

Let $P_{t-1}(g, \epsilon)$ be the probability that, for given $\left\{\left\{i_{s}\right\}_{0}^{t-1},\left\{\eta_{s}\right\}_{0}^{t-1}\right\}$, the realization of $\left\{z_{s}\right\}_{0}^{t-1}$ induces (i) $z_{t-1}=g$ and (ii) $\epsilon_{t-1}=\epsilon$.

Further, let $\pi_{z}\left(z_{t} \mid z_{t-1}\right)$ be the conditional probability. Then, the first part of (7) can be rewritten as:

$$
\begin{aligned}
& \sum_{z_{t-2}} \cdots \sum_{z_{0}} \bar{g}_{t}\left(i_{t}, g, g, \epsilon_{t-1}, \eta_{t}\right) \cdot \pi_{z}\left(g, g, z_{t-2} \ldots, z_{0}\right) \\
= & \bar{g}_{t}\left(i_{t}, g, g, 1, \eta_{t}\right) \cdot \pi_{z}(g \mid g) \cdot P_{t-1}(g, 1)+\bar{g}_{t}\left(i_{t}, g, g, 0, \eta_{t}\right) \cdot \pi_{z}(g \mid g) \cdot P_{t-1}(g, 0) .
\end{aligned}
$$

Here, $\bar{g}_{t}\left(i_{t}, g, g, 1, \eta_{t}\right)$ is either 0 or 1 , and can be calculated by $(6) . \pi_{z}(g \mid g)$ is given by the Markov transition matrix. Thus, given $P_{t-1}\left(z_{t-1}, \epsilon_{t-1}\right), \hat{y}_{t}$ can be calculated only from the information of $i_{t}$ and $\eta_{t}$, using (8) for all possible combinations of $z_{t-1}$ and $z_{t}$.

One could calculate $P_{t-1}\left(z_{t-1}, \epsilon_{t-1}\right)$ recursively. First, notice that again $P_{t-1}\left(z_{t-1}, 0\right)+$ $P_{t-1}\left(z_{t-1}, 1\right)=\pi_{z}\left(z_{t-1}\right)$, where $\pi_{z}\left(z_{t-1}\right)$ can be mechanically calculated from the Markov transition matrix and $z_{0}$. Thus, we only need to keep track of $P_{t-1}\left(z_{t-1}, 1\right)$. To obtain $P_{t}(g, 1)$, we have to calculate the probability of (i) $z_{t}=g$ and (ii) $\epsilon_{t}=1$. This can be done by just picking up the $z_{t}=g$ part in the $\hat{y}_{t}$ calculation (sum of (8) for all possible combinations of $z_{t-1}$ and $\left.z_{t}\right)$, since $\bar{g}_{t}\left(i_{t}, z_{t}, z_{t-1}, \epsilon_{t-1}, \eta_{t}\right)=1$ if $\epsilon_{t}=1$ and $\bar{g}_{t}\left(i_{t}, z_{t}, z_{t-1}, \epsilon_{t-1}, \eta_{t}\right)=0$ if $\epsilon_{t}=0$. That is,

$$
\begin{aligned}
P_{t}(g, 1)= & \bar{g}_{t}\left(i_{t}, g, g, 1, \eta_{t}\right) \cdot \pi_{z}(g \mid g) \cdot P_{t-1}(g, 1) \\
+ & \bar{g}_{t}\left(i_{t}, g, g, 0, \eta_{t}\right) \cdot \pi_{z}(g \mid g) \cdot P_{t-1}(g, 0) \\
+ & \bar{g}_{t}\left(i_{t}, g, b, 1, \eta_{t}\right) \cdot \pi_{z}(g \mid b) \cdot P_{t-1}(b, 1) \\
+ & \bar{g}_{t}\left(i_{t}, g, b, 0, \eta_{t}\right) \cdot \pi_{z}(g \mid b) \cdot P_{t-1}(b, 0)
\end{aligned}
$$


In the same way,

$$
\begin{aligned}
P_{t}(b, 1)= & \bar{g}_{t}\left(i_{t}, b, g, 1, \eta_{t}\right) \cdot \pi_{z}(b \mid g) \cdot P_{t-1}(g, 1) \\
+ & \bar{g}_{t}\left(i_{t}, b, g, 0, \eta_{t}\right) \cdot \pi_{z}(b \mid g) \cdot P_{t-1}(g, 0) \\
+ & \bar{g}_{t}\left(i_{t}, b, b, 1, \eta_{t}\right) \cdot \pi_{z}(b \mid b) \cdot P_{t-1}(b, 1) \\
+ & \bar{g}_{t}\left(i_{t}, b, b, 0, \eta_{t}\right) \cdot \pi_{z}(b \mid b) \cdot P_{t-1}(b, 0) .
\end{aligned}
$$

Note that

$$
\hat{y}_{t}=P_{t}(g, 1)+P_{t}(b, 1)
$$

by construction.

\section{Algorithm of the Economy without Fluctuations}

Denote the last period with aggregate fluctuations as $t=0$.

1. For each agent, given $z_{0}, \epsilon_{0}$, and $\eta_{0}$, simulate $i_{t}$ and $\eta_{t}$, and thus obtain the sequence of $P_{t}$ for $t=1,2, \ldots$. Sum up and obtain the aggregate labor supply $\bar{n}_{t}$ at $t=1,2, \ldots$. Check when $\bar{n}_{t}$ and the distribution of the labor supply settles down. Call that period $N_{1}$. (We used $N_{1}=40$ to 100 , depending on the starting point.) From the process of $P_{t}$, we can obtain the time series of $\hat{y}$. Instead of using $P_{t}$ in the individual decision problem, we approximate this process of $\hat{y}$ by a finite-state Markov process and use this as the individual shocks.

2. Pick $N_{2}>N_{1}$. (We used $N_{2}=1000$.) Use the average of the law of motions in $t<0$ to guess $\bar{k}_{t}, t=1,2, \ldots, N_{2}$. Call them $\bar{k}_{t}^{0}$.

3. Given the law of motion for $\bar{k}$ and the stationary value of $\bar{n}_{t}$, perform the value-function iteration (part of Krusell-Smith's [1998] method) to obtain the value function for the periods $t=N_{1}+1, \ldots, N_{2}$. Note that the decision problem is

$$
V(k, \hat{y}, \eta, \beta ; \bar{k})=\max _{c, k^{\prime}}\left\{\log c+\beta E\left[V\left(k^{\prime}, \hat{y}^{\prime}, \eta^{\prime}, \beta^{\prime} ; \bar{k}^{\prime}\right) \mid \hat{y}, \eta, \beta\right]\right\}
$$


subject to

$$
\begin{gathered}
c+k^{\prime}=r k+w \phi(\eta) \hat{y}+(1-\delta) k, \\
\bar{k}^{\prime}=H(\bar{k}), \\
k^{\prime} \geq \underline{k},
\end{gathered}
$$

$r$ and $w$ calculated from $\bar{n}$ and $\bar{k}$.

4. From $t=N_{1}$, work backwards to obtain value functions and decision rules for $t=$ $1, \ldots, N_{1}$.

$$
V_{N_{1}}(k, \hat{y}, \eta, \beta)=\max _{c, k^{\prime}}\left\{\log c+\beta E\left[V\left(k^{\prime}, \hat{y}^{\prime}, \eta^{\prime}, \beta^{\prime} ; \bar{k}_{N 1+1}\right) \mid \hat{y}, \eta, \beta\right]\right\}
$$

subject to

$$
\begin{gathered}
c+k^{\prime}=r k+w \phi(\eta) \hat{y}+(1-\delta) k, \\
\qquad k^{\prime} \geq \underline{k}, \\
r \text { and } w \text { calculated from } \bar{n}_{N_{1}} \text { and } \bar{k}_{N_{1}}^{0} .
\end{gathered}
$$

5. Simulate the economy from $t=0$, using the initial distribution at $t=0$ and the decision rules obtained above.

6. Compare the simulated path of $\bar{k}$ and $\bar{k}^{0}$. If they are not close enough, update the $\bar{k}$ sequence by the weighted average. Also obtain the new prediction rule for $\bar{k}$ by performing OLS for the new $\bar{k}_{t}, t=N_{1}, \ldots, N_{2}$.

\section{E Krusell-Smith Calibration}

To see how our model can be compared to Krusell and Smith $(1999,2002)$, we conducted the same experiment with a calibration similar to Krusell and Smith (1999, 2002). Krusell and Smith's calibration exhibits longer unemployment durations and higher unemployment rates. 
One period is considered to be a quarter following Krusell and Smith (1999, 2002). We choose $\delta=0.025$ and the average value of $\beta$ as 0.9894 . The capital share $\alpha=0.36$. The household production parameter $h$ is assumed to be 0.1 . These numbers closely follow the calibration of Krusell and Smith $(1999,2002)$. The borrowing constraint $\underline{k}$ is set at -6 , which is tighter than the "always payback constraint". We set skill premium $(\phi(s) / \phi(u))$ to 1.50 as in our baseline calibration.

As in Krusell and Smith $(1999,2002)$, aggregate shocks take the values $z \in\{b, g\}=$ $\{0.99,1.01\}$. The transition matrix is:

$$
\left[\begin{array}{ll}
p_{b b} & p_{b g} \\
p_{g b} & p_{g g}
\end{array}\right]=\left[\begin{array}{ll}
0.8750 & 0.1250 \\
0.1250 & 0.8750
\end{array}\right] .
$$

The invariant distribution is $\left[\begin{array}{ll}0.5 & 0.5\end{array}\right]$.

The skill transition matrix is set so that the stochastic process of skill is the same as the benchmark case (adjusted to the quarterly period):

$$
\left[\begin{array}{ll}
q_{u u} & q_{u s} \\
q_{s u} & q_{s s}
\end{array}\right]=\left[\begin{array}{ll}
0.995 & 0.005 \\
0.005 & 0.995
\end{array}\right]
$$

The invariant distribution is

$$
\left[\begin{array}{ll}
\chi_{u} & \chi_{s}
\end{array}\right]=\left[\begin{array}{ll}
0.5 & 0.5
\end{array}\right]
$$

We follow Krusell and Smith $(1999,2002)$ and set duration of unemployment to 1.5 quarters in good times and 2.5 quarters in bad times. In Krusell and Smith (1999, 2002), unemployment rate is set to $4 \%$ in good times and $10 \%$ in bad times. To calibrate the unemployment rates of skilled and unskilled separately, we compute $\mu_{u}^{b} / \mu_{s}^{b}$ and $\mu_{u}^{g} / \mu_{s}^{g}$ from our baseline calibration:

$$
\frac{\mu_{u}^{b}}{\mu_{s}^{b}}=2.28 \text { and } \frac{\mu_{u}^{g}}{\mu_{s}^{g}}=2.15 .
$$

Then we pick the unemployment rate of the skilled and unskilled workers so that the average unemployment rates are consistent with Krusell and Smith's calibration. We set $\mu_{u}^{b}=0.1390$, 
$\mu_{u}^{g}=0.0546, \mu_{s}^{b}=0.0610$, and $\mu_{s}^{g}=0.0254$. After following the same procedure as in the baseline calibration, the resulting $\Pi$ matrices are:

$$
\begin{aligned}
\Pi^{b b u} & =\left[\begin{array}{ll}
0.6000 & 0.4000 \\
0.0648 & 0.9352
\end{array}\right], \\
\Pi^{g b u} & =\left[\begin{array}{ll}
0.7500 & 0.2500 \\
0.1038 & 0.8962
\end{array}\right], \\
\Pi^{b g u} & =\left[\begin{array}{ll}
0.2500 & 0.7500 \\
0.0232 & 0.9768
\end{array}\right], \\
\Pi^{g g u} & =\left[\begin{array}{ll}
0.3333 & 0.6667 \\
0.0385 & 0.9615
\end{array}\right], \\
\Pi^{b b s} & =\left[\begin{array}{ll}
0.6000 & 0.4000 \\
0.0257 & 0.9743
\end{array}\right], \\
\Pi^{g b s} & =\left[\begin{array}{ll}
0.7500 & 0.2500 \\
0.0429 & 0.9571
\end{array}\right], \\
\Pi^{b g s} & =\left[\begin{array}{ll}
0.2500 & 0.7500 \\
0.0107 & 0.9893
\end{array}\right], \\
\Pi^{g g s} & =\left[\begin{array}{ll}
0.3333 & 0.6667 \\
0.0173 & 0.9827
\end{array}\right] .
\end{aligned}
$$

For $\beta$, we follow the calibration of Krusell and Smith $(1999,2002)$. The transition probabilities from state $\beta_{i}$ to state $\beta_{j}, \omega_{i j}$ for the quarterly model are

$$
\left[\begin{array}{ccc}
\omega_{l l} & \omega_{l m} & \omega_{l h} \\
\omega_{m l} & \omega_{m m} & \omega_{m h} \\
\omega_{h l} & \omega_{h m} & \omega_{h h}
\end{array}\right]=\left[\begin{array}{ccc}
119 / 120 & 1 / 120 & 0 \\
1 / 960 & 958 / 960 & 1 / 960 \\
0 & 1 / 120 & 119 / 120
\end{array}\right] .
$$

The values of $\beta_{l}, \beta_{m}, \beta_{h}$ follow Krusell and Smith (1999, 2002). In particular, $\beta_{l}=0.9858$, $\beta_{m}=0.9894$, and $\beta_{h}=0.9930$.

We follow the same computational procedure as in the benchmark case. The average value of $\bar{k}$ in the fluctuating economy turns out to be around 46 , and we conducted the experiment at $\bar{k}=46.0$. To highlight the difference from the benchmark model, Table 3 summarizes the 


\begin{tabular}{|c||c|c|c|c|c|c|}
\hline \multicolumn{1}{|c||}{} & \multicolumn{5}{c|}{ asset level (in total wealth distribution) } \\
\cline { 2 - 7 } & constrained & bottom $1 \%$ & $10 \%$ & $50 \%$ & $90 \%$ & $99 \%$ \\
\hline \hline$\eta=u, \epsilon=0$ & $1.807 \%$ & $1.024 \%$ & $0.681 \%$ & $0.315 \%$ & $0.286 \%$ & $0.406 \%$ \\
\hline$\eta=u, \epsilon=1$ & $0.629 \%$ & $0.440 \%$ & $0.321 \%$ & $0.127 \%$ & $0.171 \%$ & $0.334 \%$ \\
\hline$\eta=s, \epsilon=0$ & $1.427 \%$ & $0.874 \%$ & $0.551 \%$ & $0.266 \%$ & $0.325 \%$ & $0.536 \%$ \\
\hline$\eta=s, \epsilon=1$ & $0.218 \%$ & $0.141 \%$ & $0.090 \%$ & $0.042 \%$ & $0.162 \%$ & $0.431 \%$ \\
\hline
\end{tabular}

Table 3: The values of $\lambda$ for $\beta=0.9894, \bar{k}=46$, and $z=b$

results that corresponds to Table $1 \mathrm{~b}$ in the main text. (That is, the result when $z=b$.) In this experiment, the average value of $\lambda$ for the unskilled workers is $0.283 \%$ (while the skilled $\lambda$ is $0.128 \%)$. This is much larger than the corresponding average numbers $(0.110 \%$ with low aggregate capital and 0.096\% with high aggregate capital) in Krusell and Smith (2002). When $z=g$, the average value of $\lambda$ for the unskilled workers is $0.096 \%$ (while the skilled $\lambda$ is $0.067 \%)$. Again, this is larger than the corresponding average numbers $(0.089 \%$ with low aggregate capital and $0.087 \%$ with high aggregate capital) in Krusell and Smith (2002). 


\section{References}

[1] Aiyagari, S. Rao (1994). "Uninsured Idiosyncratic Risk and Aggrigate Saving," Quarterly Journal of Economics 109, 659-684.

[2] Atkeson, Andrew and Christopher Phelan (1994). "Reconsidering the Costs of Business Cycles with Incomplete Markets," in Stanley Fischer and Julio J. Rotemberg, eds., NBER Macroeconomics Annual 1994, National Bureau of Economic Research.

[3] Barlevy, Gadi (2004). "The Cost of Business Cycles under Endogenous Growth," American Economic Review 94, 964-990.

[4] Budría Rodríguez, Santiago; Javier Díaz-Giménez; Vincenzo Quadrini; and José-Victor Ríos-Rull (2002). "Updated Facts on the U.S. Distributions of Earnings, Income, and Wealth," Federal Reserve Bank of Minneapolis Quarterly Review 26, 2-35.

[5] Card, David (1995). "Earnings, Schooling, and Ability Revisited." In Solomon Polachek, ed., Research in Labor Economics Vol. 14. JAI Press: Greenwich Connecticut.

[6] Hansen, Gary D. and Ayşe İmrohoroğlu (1992). "The Role of Unemployment Insurance in an Economy with Liquidity Constraints and Moral Hazard," Journal of Political Economy $100,118-142$.

[7] İmrohoroğlu, Ayşe (1989). "The Cost of Business Cycles with Indivisibilities and Liquidity Constraints," Journal of Political Economy 97, 1364-1383.

[8] Keane, Michael and Eswar Prasad (1993). "Skill Levels and the Cyclical Variability of Employment, Hours, and Wages," IMF Staff Papers 40, 711-743.

[9] Krusell, Per and Anthony A. Smith, Jr. (1998). "Income and Wealth Heterogeneity in the Macroeconomy," Journal of Political Economy 106, 867-896. 
[10] Krusell, Per and Anthony A. Smith, Jr. (1999). "On the Welfare Effects of Eliminating Business Cycles," Review of Economic Dynamics 2, 245-272.

[11] Krusell, Per and Anthony A. Smith, Jr. (2002). "Revisiting the Welfare Effects of Eliminating Business Cycles," mimeo. University of Rochester and Carnegie Mellon University.

[12] Lindquist, Matthew J. (2004). "Capital-Skill Complementarity and Inequality Over the Business Cycle," Review of Economic Dynamics 7, 519-540.

[13] Lucas, Robert E. Jr. (1987). Models of Business Cycles, Basil Blackwell: New York.

[14] Lucas, Robert E. Jr. (2003). "Macroeconomic Priorities," American Economic Review $93,1-14$.

[15] Mayer, Adalbert (2002). "Education, Self-Selection and Intergenerational Transmission of Abilities," mimeo. University of Rochester.

[16] Mincer, Jacob (1991). "Education and Unemployment," NBER Working Paper, \#3838.

[17] Murphy, Kevin M., and Finis Welch (1992). "The Structure of Wages," Quarterly Journal of Economics 107, 285-326.

[18] Obstfeld, Maurice (1994). "Evaluating Risky Consumption Paths: The Role of Intertemporal Substitutability," European Economic Review 38, 1471-86.

[19] Statistics Canada (1998). Education Quarterly Review Vol.5, no.2.

[20] Topel, Robert (1993). "What Have We Learned from Empirical Studies of Unemployment and Turnover?" American Economic Review 83, 110-115.

[21] Wolff, Edward N. (1995). Top Heavy, The New Press: New York. 